\title{
Review Article \\ Pluripotent Stem Cells: Current Understanding and Future Directions
}

\author{
Antonio Romito ${ }^{1}$ and Gilda Cobellis ${ }^{2}$ \\ ${ }^{1}$ Centogene, Schillingallee 68, 18057 Rostock, Germany \\ ${ }^{2}$ Department of Biophysics, Biochemistry and General Pathology, Second University of Naples, Via L. de Crecchio 7, 80131 Napoli, Italy
}

Correspondence should be addressed to Gilda Cobellis; g.cobellis@unina2.it

Received 22 June 2015; Accepted 26 August 2015

Academic Editor: Zhaohui Ye

Copyright ( 2016 A. Romito and G. Cobellis. This is an open access article distributed under the Creative Commons Attribution License, which permits unrestricted use, distribution, and reproduction in any medium, provided the original work is properly cited.

Pluripotent stem cells have the ability to undergo self-renewal and to give rise to all cells of the tissues of the body. However, this definition has been recently complicated by the existence of distinct cellular states that display these features. Here, we provide a detailed overview of the family of pluripotent cell lines derived from early mouse and human embryos and compare them with induced pluripotent stem cells. Shared and distinct features of these cells are reported as additional hallmark of pluripotency, offering a comprehensive scenario of pluripotent stem cells.

\section{Introduction}

The first evidence suggesting the existence of "special cells," today known as stem cells, able to self-renew and to differentiate into specialized cell types, dates back in 1961 when two scientists, Drs. James A. Till, a biophysicist, and, Ernest A. McCulloch, a hematologist, accidentally observed that the intravenous injection of bone marrow cells in previously irradiated mice led to the formation of colonies of proliferating cells in the spleen of those animals. The injected cells were blood-forming progenitor cells, able to fully regenerate the blood cells, and opening toward the clinical use of bone marrow transplantation for haematopoietic disorders [1]. Since then, the following works have reported the isolation, identification, and characterization of different types of stem cells.

Today, the field of stem cell research is in a rapid and dynamic expansion, representing one of the most exciting areas in life science. The importance of studying the biology of stem cells relies in their wide range of applications. In basic research, stem cells represent a powerful system to study gene function and the physiological processes occurring during development. In biomedical research, stem cells are used to study the pathogenesis of human genetic disease, to identify new diagnostic and prognostic biomarkers, and to test improved drugs. However, what renders stem cell research extremely important is the vast potential of clinical applications of these cells. Their capacity to differentiate into specific cell types could be used in regenerative medicine to treat damaged or diseased tissues through cell-replacement therapies. Recently, the US Food and Drug Administration (FDA) approved clinical trials using stem cells for the treatment of heart disease [2]. Although some stem cell therapies are in clinical trials, a lot more basic research is needed before therapies using differentiated stem cell-derivatives can be applied in humans.

Over the last years, the major advances and discoveries in stem cell research have been made in pluripotent stem cells (PSCs). The definition of pluripotent stem cell is based on two properties: self-renewal and potency. The self-renewal is the capacity of the stem cells to divide indefinitely, producing unaltered cell daughters maintaining the same properties of the progenitor cell. In particular conditions or under specific signals, a stem cell is able to exit from self-renewal and engage a program leading to differentiate into specialized cell types deriving from the three germ layers (ectoderm, endoderm, and mesoderm) [3].

There are two types of PSCs, embryonic stem cells (ESCs) and induced pluripotent stem cells (iPSCs). ESCs are derived from the inner cell mass (ICM) of preimplantation embryos $[4,5]$ and can be indefinitely maintained and expanded in 
the pluripotent state in vitro. Pluripotent stem cells can also be obtained by inducing dedifferentiation of adult somatic cells through a recently developed in vitro technology, known as cell reprogramming $[6,7]$. Similarly to ES, iPS cells can be expanded indefinitely and they are capable to differentiate in all the derivatives of the three germ layers.

The aim of this review is to provide a detailed overview of the recent discoveries in ESC and iPSC research. We will compare murine and human ESCs, highlighting common and distinct features of pluripotency. Particularly, we will discuss the current notion of "ground state" of pluripotency for mESCs and whether such a naïve state can exist for hESCs. Furthermore, we will review the most recent advances in iPSCs and point out some key hurdles in cell reprogramming. Finally, we will discuss the potential applications of pluripotent stem cells, with a special emphasis on iPSCs as promising and exciting source to model human diseases and to develop cell-based therapies.

\section{Embryonic Stem Cells}

2.1. Mouse Embryonic Stem Cells: The "Ground State" of Pluripotency. Murine ESCs (mESCs) were first isolated in 1981 from the ICM of mouse blastocyst, the part that will give rise to the embryo. They can be maintained indefinitely in culture through self-renewing division and, more importantly, are pluripotent, retaining the ability to differentiate into all somatic cell lineages [8]. mESCs were originally established and maintained in presence of serum on mouse embryonic fibroblasts (MEFs) as feeder cells, growing as round-shaped colonies of tightly packed cells, suggesting close cell membrane contacts and inability to "walk" on the plate. Maintaining of the self-renewing state of mESCs can be obtained by adding the cytokine leukaemia inhibitory factor (LIF) in culture medium [9]. The LIF/gp130 receptor interaction on the cell surface activates Stat3, the downstream effector of multiple intracellular pathways, including JAK/Stat3, PI3K/Akt, and MAP/ERK [10]. In response to the activation of these pathways, Stat 3 is phosphorylated and forms homo- or heterodimers that translocate from the cytoplasm to nucleus, where it binds to specific DNA elements activating the transcription of pluripotency factors (Figure 1(a)) [11]. In an attempt to find molecules able to guarantee the self-renewal, the transcription factor CP2-like 1 (Tfcp2l1) was identified as the target of the LIF/Stat3mediated pathway controlling mESC self-renewal, and forced expression of Tfcp2l1 was shown to recapitulate the selfrenewal-promoting effect of LIF [12].

However, LIF alone is not sufficient to maintain mESC self-renewal, as the cells also require the presence of foetal calf serum. Bone morphogenetic proteins (BMPs), members of the transforming growth factor (TGF) $\beta$ family, present in the serum, act in conjunction with LIF, enhancing the selfrenewal and pluripotency of mESCs $[11,13]$. The binding of BMP4 to its receptors (BMPR1/2) triggers phosphorylation of Smad proteins (Smad1, Smad5, and Smad8). Once phosphorylated, they form a complex with Smad 4 and translocate into the nucleus [14], where they activate expression of inhibitor of differentiation (Id) gene 1 (Id-1), critical for suppressing ESC differentiation and sustaining pluripotency [11]. Overexpression of Id1 led mESCs to self-renew in absence of BMP4 and its disruption led to decreased Nanog expression and mESCs failed to maintain self-renewal [15] (Figure 1(a)).

Hence, LIF and BMP signalling pathways play a central role in maintaining the pluripotent phenotype. In absence of any supplements to the culture medium, mESCs tend to lose their pluripotency and self-renewing capacity due to fibroblast growth factor 4 (FGF4) secreted by cells and concomitant activation of the MAPK pathway, which drives mESCs to differentiation. Inhibition of the FGF4-mediated differentiation pathway can therefore perpetuate the pluripotent state [16].

Based on this observation, Austin Smith and coworkers pioneered the use of small-molecule inhibitors to block the FGF4 pathway via MEK and GSK3 inhibition, enabling mESCs to grow in minimal, serum-free media. They found that simultaneous inhibition of the MAPK and GSK3 pathways by PD0325901 and CHIRON99021, respectively, allowed robust propagation of mESC cultures with concomitant maintenance of pluripotency (Figure 1(b)) [17]. The pluripotent ground state is achieved by repressing prodifferentiation Mek/Erk/Klf2 axis [18].

Many laboratories started to culture mESCs without serum by using these two small kinase inhibitors, known as $2 \mathrm{i}$. mESCs grown in $2 \mathrm{i}$ medium are more homogenous in morphology and exhibit a more uniform gene expression profile than mESCs grown in serum, which now represent a less attractive model system for several reasons. Firstly, serumcultured mESCs are morphologically heterogeneous, are prone to aneuploidy, and have altered differentiation potential, as a result of fluctuations in the expression of pluripotency and lineage-specific factors. In addition, different serum batches can cause variations between mESC cultures of different laboratories in terms of morphology and gene expression profile due to undefined factor composition [19].

Recent data demonstrated that mESCs do not faithfully mimic ICM cells. It seems that mESCs emerge from a subpopulation of ICM cells that become positive to Blimp1, a germ cell-specific factor, suggesting that mESCs have a germ cell origin and that their derivation is triggered by activation of a transcriptional programme specific to primordial germ cells (PGCs) [20]. All together, these findings demonstrate that mESCs grown in serum are in a metastable condition between ICM cells and epiblast stem cells (EpiSCs), whereas mESCs grown in $2 \mathrm{i}$ are in a uniform "ground state" condition, in other words, a condition, which more closely resembles the pluripotent cells of ICM before embryo formation.

Thus, the use of $2 \mathrm{i}$ promotes "ground state" pluripotency by blocking factors associated with lineage specification [19] and reducing the fluctuating expression of pluripotency genes observed in serum [21]. In addition, $2 \mathrm{i}$ conditions proved to be successful in deriving germline-competent ESCs from all mouse strains and rats $[22,23]$.

To reveal the true identity of naive pluripotent stem cells, transcriptome and epigenome comparisons were performed between mESCs grown in $2 \mathrm{i}$ and serum.

Genome-wide RNA-Sequencing (RNA-seq) experiments showed that $75 \%$ of genes are expressed at similar levels in $2 \mathrm{i}$ and serum and pluripotency genes, such as Oct4, Nanog, 


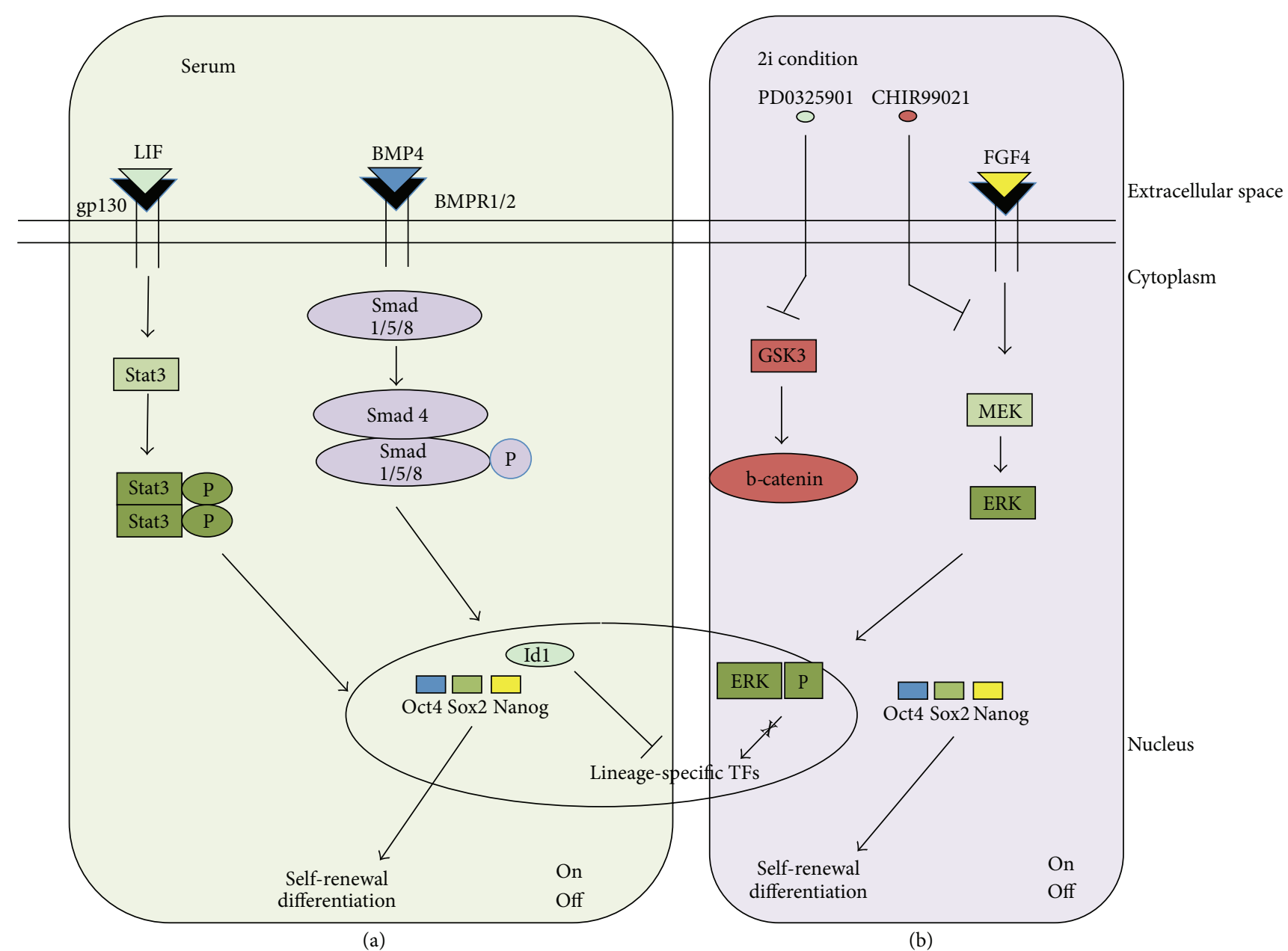

FIGURE 1: Signal transduction pathways in serum- and 2i-cultured mESCs.

Sox2, Rex1, Klf2, and Klf4, are similarly expressed. Others, including $c / N-M y c$, Eras, and $I d$ genes, thought to be essential for serum-grown mESC, are almost absent in 2i-cultured mESCs, suggesting that these genes do not per se control pluripotency. Gene-ontology (GO) analysis revealed that genes highly expressed in serum-grown mESCs are enriched in development term, suggesting that mESCs grown in these conditions may be more prone to differentiate. In contrast to this hypothesis, mESCs cultured in serum show similar kinetics and potential to mESCs in $2 \mathrm{i}$ medium during in vitro differentiation assays. A second term highly enriched in serum-grown mESCs is cell cycle regulation. The doubling time of mESCs is around 10-14 hours, with $65 \%$ of cells in Sphase and only $15 \%$ in G1-phase. Although data on cell cycle regulation are not conclusive, a recent study showed that G1phase of mESCs grown in $2 \mathrm{i}$ is shorter than that of mESCs cultured in serum, due to increased expression of cell cycle inhibitors [24].

GO analysis of genes highly expressed in $2 \mathrm{i}$ revealed a significant enrichment of terms associated with metabolic processes, likely due to inhibition of glucose metabolism by $2 \mathrm{i}$ molecules [19]. However, recent efforts showed that other metabolites (i.e., amino acids) control stem cell plasticity, acting as mediators of crosstalk between metabolic flux, cellular signalling, and epigenetic regulation of cell fate [25]. Threonine is the only amino acid required for pluripotency and is intimately associated with S-adenosyl-methionine metabolism (SAM) [26]. Depletion of threonine in mESCs decreases SAM activity with a consequent reduction in trimethylation of lysine 4 on histone 3 (H3K4), resulting in slow growth and increased differentiation.

Recently, other amino acids have been shown to play in this complex scenario. The nonessential amino acid L-Proline acts as a signalling molecule by remodelling methylation profiles of histone 3 on lysine 9 and 36 residues (H3K9 and H3K36), inducing a transition state between mESCs and EpiSCs [27]. The most intriguing feature of mESCs is that they are able to switch their transcriptional profile between $2 \mathrm{i}$ and serum conditions, suggesting that the transcriptional state is not stable and that the so-called signature of mESCs only reflects the culture conditions.

Chromatin immunoprecipitation and deep sequencing (ChIP-seq) was used to analyse posttranslational histone modifications: $\mathrm{H} 3 \mathrm{~K} 4 \mathrm{me} 3$ and $\mathrm{H} 3 \mathrm{~K} 36 \mathrm{me} 3$ associated with active promoters and transcribed genes; H3K27me3 linked to silencing; H3K9me3 associated with constitutive 
heterocromatin and imprinted genes. The H3K9me3 ChIPseq results obtained from mESCs grown in $2 \mathrm{i}$ and serum were identical. Genes upregulated in $2 \mathrm{i}$ showed increased $\mathrm{H} 3 \mathrm{~K} 4 \mathrm{me} 3$ marks on active promoters and higher levels of $\mathrm{H} 3 \mathrm{~K} 36 \mathrm{me} 3$ and a substantial reduction of repressive $\mathrm{H} 3 \mathrm{~K} 27 \mathrm{me} 3$ mark. In contrast, upregulated genes in mESCs grown in serum showed increased H3K27me3 marks and no significant change in $\mathrm{H} 3 \mathrm{~K} 4 \mathrm{me} 3$ deposition. Furthermore, the majority of $\mathrm{H} 3 \mathrm{~K} 27$ me 3 marks coexisted with $\mathrm{H} 3 \mathrm{~K} 4 \mathrm{me} 3$ in serum conditions. Extensive studies of these so-called bivalent genes revealed that they are mainly involved in the activation of differentiation and are in paused status. Polymerase II (Pol II) occupancy was found over the coding gene bodies instead of transcriptional start sites [19, 28, 29]. Of these genes, only $33 \%$ are conserved in $2 \mathrm{i}$ compared to serum, suggesting the existence of a balance between the pluripotency network and lineage specifiers, which inhibit differentiation.

Furthermore, the role of DNA methylation across distinct states was also investigated by mapping genome-wide 5methylcytosine (5-mC) and 5-hydroxymethylcytosine (5$\mathrm{hmC}$ ) in $\mathrm{mESCs}[30,31]$. While 5 - $\mathrm{mC}$ represses transcription, elevated 5-hmC levels are associated with increased gene expression. 2i-cultured mESCs display altered distribution of $5-\mathrm{mC}$ and $5-\mathrm{hmC}$ at regulatory elements as well as reduced levels of 5-mC compared to serum. Conversely, EpiSCs show increased 5-mC together with reduced 5-hmC in promoters, in line with their developmental restriction [32].

Switching to $2 \mathrm{i}$ induces the rapid onset of "ground-state" gene expression and global DNA demethylation. Mechanistically, a robust hypomethylated state is achieved by repression of de novo methylases by PRDM14 and by ten-elevated translocation (TET) 1 and 2-mediated 5-hmC conversion, together controlling transition to "ground-state" pluripotency $[32,33]$. Dynamic activation of promoter and enhancers surrounding TET1 and TET2 during the different phases of development controls the progression from pluripotent state toward differentiation [34].

\subsection{Transcription Factor Heterogeneity in Stem Cells: A Way} to Explore the "Future". The pluripotent state of mESCs is achieved by a coordinated action of gene networks together with multiple signalling pathways responding to environmental cues. This circuitry is established upon formation of pluripotent cells within the blastocyst and persists in epiblast cells until gastrulation [35-37]. At this time, levels of the pluripotency-associated TFs Oct4 and Nanog decrease, and pluripotency can no longer be sustained.

Oct 4 was identified over 20 years ago as a transcription factor (TF) specific to early embryogenesis. It is expressed in oocytes, early embryo, embryonic carcinoma cells, and mESCs but is not found in adult differentiated tissues $[38,39]$. Expression levels of Oct4 mRNA is similar in unfertilized oocytes and in zygote, suggesting the existence of maternal transcripts that decrease at the 2- and 4-cell stage of development. Upon zygotic genome activation, upregulation of Oct4 expression is observed between the morula stage at 2.5 days post coitum $(\mathrm{dpc})$ and the blastocyst stage at $3.5 \mathrm{dpc}$. Rapid downregulation of Oct 4 protein begins in cells differentiating into trophectoderm lineage, while expression levels remain high in ICM cells, in the epiblast at $5.5 \mathrm{dpc}$, and in germ cell lineage during gastrulation, confirming the role of Oct4 in the maintenance and self-renewal of pluripotent stem cells [40]. No expression is visible from $9.5 \mathrm{dpc}$ onwards, except in PGCs. Thus, Oct4 is spatially and temporally regulated during early murine development and contributes to cell fate decisions. In 7- to 8-day-old mice, Oct4 reaches a minimal threshold level, corresponding to irreversible loss of pluripotency, with concomitant Nanog silencing by DNA methylation. This is the point at which the pluripotency network is definitely dismantled [35].

Pluripotency is acquired not only by inhibiting lineage specifiers [41], but also by recruiting chromatin-remodelling complexes to regulatory regions and their binding to closed chromatin domains. Oct4 is therefore emerging as a pioneer $\mathrm{TF}$, able to recruit factors with diverse functions (i.e., TFs, chromatin remodelling proteins) to establish gene-specific programmes [42].

Another intriguing features of pluripotency is its reliance on gene expression heterogeneity, firstly described in a work on the presumptive monoallelic regulation of Nanog [43]. Nanog was originally identified in a genetic screen for molecules that facilitate mESC self-renewal in absence of LIF [44, Chambers, 2007 \#300]. Subsequent analyses revealed that Nanog acts as a differentiation rheostat through a complex transcriptional and translational regulation able to modify its expression levels without affecting mESC pluripotency [45-47]. It is now known that several TFs are expressed heterogeneously in mESCs depending on the mode of transcriptional as well as posttranscriptional regulation, such as protein synthesis and cell cycle dynamics [48]. TFs heterogeneity is linked to the existence of various functional states in pluripotent stem cells and to the fact that individual cells in a mixed population have a propensity either to self-renew or commit to differentiation. Thus, the working hypothesis is that stochastic fluctuations of TFs provide opportunities for mESCs either to modulate their potential fate or to remain pluripotent by exploring multiple lineage options. This mechanism confers robustness to such an important cell population as pluripotent stem cells by preserving both the identity of cells and their capacity to differentiate in response to different signalling pathways.

2.3. Human Embryonic Stem Cells. The first human embryonic stem cells (hESCs) were derived from blastocysts produced by in vitro fertilization (IVF) in 1998 [5], using immunosurgical procedures similar to those utilized by Evans and Kaufman 17 years earlier to derive the first mESC line. In the following years, few other hESC lines were obtained [49,50] until 2004, when a new standardized protocol and a well-defined culture medium allowed efficient derivation of hESCs [51].

The establishment of hESC lines showed that, like mESCs, hESCs can grow indefinitely in vitro, maintaining their karyotype and pluripotent capacity [5, 49-51]. The undifferentiated state of hESCs and their developmental potential to differentiate into all cell types of the body were confirmed by several assays in vitro and in vivo [52]. 


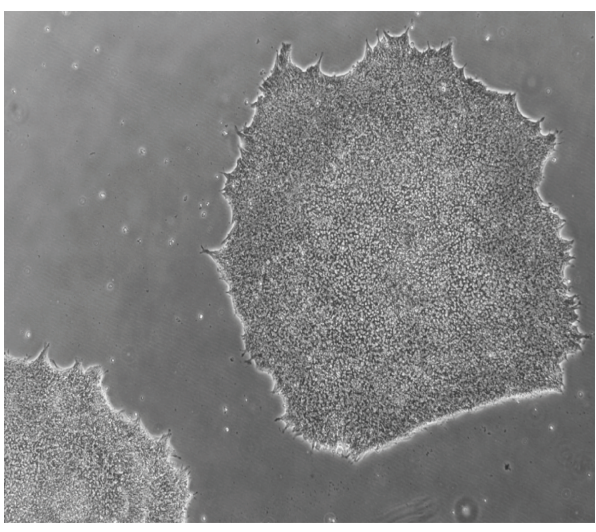

hESC

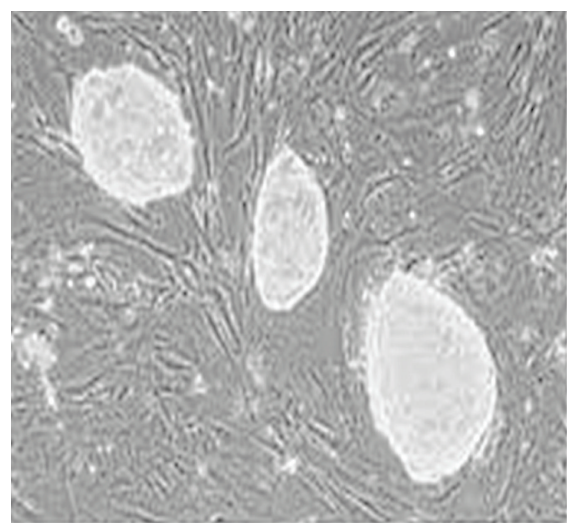

mESC

FIgUre 2: Morphology of hESCs and mESCs.

The most commonly used in vivo method for determining whether a hESC line is pluripotent is transplantation in immune-deficient mice to assess its ability to form teratomas. A teratoma is a nonmalignant tumour composed of a disorganized mixture of cells and tissues deriving from the three germ layers [53]. Formation of primate chimeras, the most stringent method to test pluripotency in rodents, cannot be undertaken in human, due to ethical issues. To overcome this barrier, interspecies chimeras have been generated through injection of hESCs into mouse blastocysts [54]. Although it has been shown that hESCs can be integrated into the ICM, human cells poorly contribute to mouse embryo suggesting that the method is inefficient [54]. Therefore, we still lack a definitive functional assay to test pluripotency in human.

\subsection{Differences between Mouse and Human Embryonic Stem} Cells. mESCs and hESCs show equivalent developmental potential, as would be expected considering their common embryonic origin. However, several reports have described significant differences between the two cell lines. In terms of colony morphology, hESCs grow as flat and compact colonies unlike the multilayered and rounded colonies formed by mESCs [5] (Figure 2). Other important differences concern growth conditions, transcriptional networks, signalling pathways that controls self-renewal and pluripotent state, and epigenetic signatures $[55,56]$.

To decipher the transcriptional network in hESCs, it is crucial to understand the mechanism(s) regulating pluripotency. Several studies have shown that maintenance of selfrenewal and pluripotency in hESCs involves very different signalling pathways from those in mESCs. While mESCs are dependent on LIF and Bmp4, LIF is dispensable for hESCs $[57,58]$, and the presence of BMP4 in culture medium induces hESC differentiation into trophoblasts [59]. hESCs also require other factors such as Activin A/Nodal, FGF2 [60-62] and IGF [63]. Activin A and Nodal, members of the transforming growth factor (TGF- $\beta$ ) superfamily, play a role in maintaining hESC self-renewal by promoting NANOG transcription via SMAD2/3 signalling [60-62]. SMAD2/3 proteins directly bind and regulate expression of NANOG [64]. In addition, recent ChIP-seq analysis of hESCs showed the binding of SMAD2/3 to promoter regions of other genes involved in self-renewal such as OCT4, TERT, MYC, and DPPA4, with SMAD2/3 sharing approximately onethird overlap with NANOG genomic targets, suggesting their cooperation in transcriptional control of pluripotency genes [65].

Another report showed that SMAD3 cooccupies OCT4 genomic binding sites across the genome in both hESCs and mESCs [66], indicating a more extensive involvement of SMAD2/3 signalling in sustaining pluripotency in hESCs.

Unlike Nodal and Activin A, the exact mechanism(s) by which FGF2 signalling is able to sustain hESC pluripotency is still not clear. This is partly due to the complexity of pathways influenced by FGF signalling and to the varying culture conditions employed by different laboratories. FGF2 signalling was reported to sustain NANOG expression by cooperating with Nodal and Activin A signalling [61, 67] through the MEK/ERK pathway [68]. However, the way in which the MEK/ERK pathway regulates NANOG expression remains essentially unknown. Large-scale analyses undertaken to profile the global phosphoproteome in hESCs after FGF2 stimulation identify phosphorylated players of canonical pathways involved in self-renewal and pluripotency, such as PI3K/Akt, MAPK/ERK, and Wnt, as well as pluripotency regulators including OCT4, SOX2, RIF1, SALL4, DPPA4, and p53 $[69,70]$. These data suggest possible events occurring downstream of FGF2-FGF receptor interaction. In addition to sustaining expression of pluripotency-associated genes, the FGF and Activin A/Nodal pathways synergize to inhibit BMP signalling [64], which represses self-renewal and promotes differentiation by SMAD1/5/8 binding to NANOG promoter, thereby inhibiting its expression.

IGF has also been implicated in pluripotency maintenance since it was observed that blocking the IGF2-IGF1 receptor pathway reduced survival and clonogenicity of hESCs [63]. IGF is able to sustain pluripotency through activation of the PI3K pathway. Inhibition of either IGF or PI3K signalling efficiently promotes differentiation of hESCs [71]. PI3K maintains hESC pluripotency by suppressing Activin A/Nodal-triggered pathways [71], thus redirecting SMAD2/3 activity to pluripotency rather than differentiation. 
In conclusion, $\mathrm{PI} 3 \mathrm{~K} /$ Akt cooperate with Activin A to promote a pluripotent state and that Activin A has context-dependent functions in promoting and antagonizing self-renewal pathways.

OCT4, NANOG, and SOX2 form the pluripotencyregulating network in hESCs, as in mESCs [72]. RNA interference-mediated knockdown of these genes in hESCs results in loss of pluripotency and self-renewal [73-75].

ChIP technologies were used to map the genomic binding sites of these proteins in hESCs $[76,77]$. Extensive OCT4, NANOG, and SOX2 cobinding was found at numerous genomic target sites localized in active as well as in silent genes, supporting their role in pluripotency and self-renewal through autoregulatory activation, and repression of key genes involved in developmental processes [77].

Although mESCs and hESCs share the same pluripotent transcriptional circuitry, a limited overlap was observed between OCT4 and NANOG target genes, suggesting differences in the networks controlled by the two TFs in the two species [76, 77]. This result was confirmed by other techniques including microarray, serial analysis of gene expression (SAGE), and massively parallel signature sequencing (MPSS) [78, 79].

Other epigenetic signatures of hESCs, different from their mouse counterparts, are exemplified by X chromosome status. Female mESCs are in a pre-X inactivation state carrying two active $\mathrm{X}$ chromosomes $\left(\mathrm{X}_{\mathrm{a}} \mathrm{X}_{\mathrm{a}}\right)$. Upon differentiation, one of the two $\mathrm{X}$ chromosomes becomes transcriptionally silenced $\left(\mathrm{X}_{\mathrm{i}} \mathrm{X}_{\mathrm{a}}\right)$ through the $\mathrm{X}$-chromosome inactivation (XCI) process [80]. The active $\mathrm{X}$ chromosome therefore represents an epigenetic hallmark of an undifferentiated state in female mESCs. By contrast, XCI is already established in the majority of undifferentiated female hESCs. XCI status was reported to vary greatly between different hESC lines and subcultures of a single cell line [81-83]. Three distinct states of XCI were described for hESCs $[84,85]$. Class I cells possess two active $\mathrm{X}$ chromosomes $\left(\mathrm{X}_{\mathrm{a}} \mathrm{X}_{\mathrm{a}}\right)$ and, like mESCs, $\mathrm{X}$-inactive specific transcript (XIST) is upregulated, coats $\mathrm{X}$ chromosome, and triggers accumulation of H3K27me3, upon differentiation. However, hESCs in the pre X-inactivation state in vitro are epigenetically unstable, readily proceeding toward class II and subsequently class III $[86,87]$. Class II cells contain one inactivated $\mathrm{X}$ chromosomes $\left(\mathrm{X}_{\mathrm{a}} \mathrm{X}_{\mathrm{i}}\right)$, coated by XIST and marked by H3K27me3. Class II hESCs may further progress toward class III [87], where the silent state of the inactive $\mathrm{X}$ chromosome is largely maintained, while XIST expression and the $\mathrm{H} 3 \mathrm{~K} 27 \mathrm{me} 3$ histone mark are lost, leading to partial reactivation of some $\mathrm{X}_{\mathrm{i}}$-linked genes [88]. In class III cells, XIST is silenced through methylation of its promoter, and upon differentiation class III cells do not reexpress XIST and do not acquire H3K27me3 marks [88].

A recent publication reported that oxygen tension is one factor favouring the establishment of XCI in hESCs. Derivation and maintenance of hESCs are conventionally performed in atmospheric concentration $\left(20 \% \mathrm{O}_{2}\right)$ [5, 49-51], which is a hyperoxic condition compared to physiological levels $\left(5 \% \mathrm{O}_{2}\right)$ [89]. hESCs derived at $5 \% \mathrm{O}_{2}$ tension preferentially remain in class $\mathrm{I}$, as demonstrated by the absence of XIST expression, high levels of methylation of XIST promoter, biallelic expression of $\mathrm{X}$-linked genes, and the ability to undergo random $\mathrm{X}$ inactivation upon differentiation [88]. When cells derived and grown in hypoxia conditions are exposed and cultured at $5 \% \mathrm{O}_{2}$, they show signs of $\mathrm{XCI}$ progressing irreversibly toward class II and then toward class III [88]. This finding strongly supports the observation that hESCs are epigenetically unstable in vitro in terms of XCI, since it was demonstrated that human preimplantation blastocysts contain cells in the pre-X inactivation state [90].

A successful conversion of XIST-dependent class II cells into class I was reported in another work, in which hESC medium was supplemented with sodium butyrate, a histone deacetylase inhibitor (HDACi), and an S-adenosylhomocysteine (SAH) hydrolase inhibitor (DZNep), able to deplete cellular levels of enhancer of zeste homolog 2 (EZH2) and to remove H3K27me3 marks from the genome [91, 92].

Derivation in a naïve state was reported to be unsuccessful for class III hESCs [91]. In addition, class I hESCs were derived in normoxic conditions by adding both sodium butyrate and DZNep to culture medium, suggesting that these two molecules are able to prevent XCI and maintain the cells in class I for several passages [92].

To date, there are no reports in the literature of any other epigenetic signature characterizing hESCs, and it would be interesting to discover whether the instability associated with the inactivation process reflects a more general epigenetic instability in hESCs.

2.5. Defining the Pluripotent "Ground State" in hESCs. Differences in morphology, growth factor dependency, and epigenetic modifications observed in mESCs and hESCs were initially thought to reflect species-specific variations of pluripotency. This idea was challenged when EpiSCs were isolated from epiblasts of postimplantation murine blastocysts $[93,94]$. Although EpiSCs fulfilled some crucial criteria of pluripotency (i.e., teratoma formation, expression of pluripotency-associated TFs), transcriptome analysis showed that independent EpiSC lines were similar to each other, but different from mESCs. Interestingly the gene expression profile of EpiSCs is more similar to that of postimplantation epiblast than preimplantation ICM, consistent with their embryonic developmental stage $[93,94]$. The observed differences between mESCs and EpiSCs indicate the existence of two distinct pluripotent states, recently termed naïve and primed, respectively, belonging to two different developmental stages [95].

Interestingly, hESCs share many features with EpiSCs (Figure 3(a)). Like hESCs, EpiSCs grow as flat and compacted colonies and show intolerance to passaging at single cells, and their derivation and long-term maintenance are strictly depended on FGF2 and Activin, but not on LIF and/or BMP4 as is the case with mESCs $[93,94,96]$. Again, like hESCs, EpiSCs are able to differentiate into trophectoderm in presence of BMP4 $[59,97]$, whereas mESCs have little or no ability to contribute to trophectoderm lineages in chimeric embryos [98]. ChIP experiments in mESCs, EpiSCs, and hESCs to identify OCT4 target sites showed a limited overlap of OCT4 targets in hESCs and mESCs $[76,77]$, but a 7-fold greater overlap between hESCs and mEpiSCs [94], suggesting 

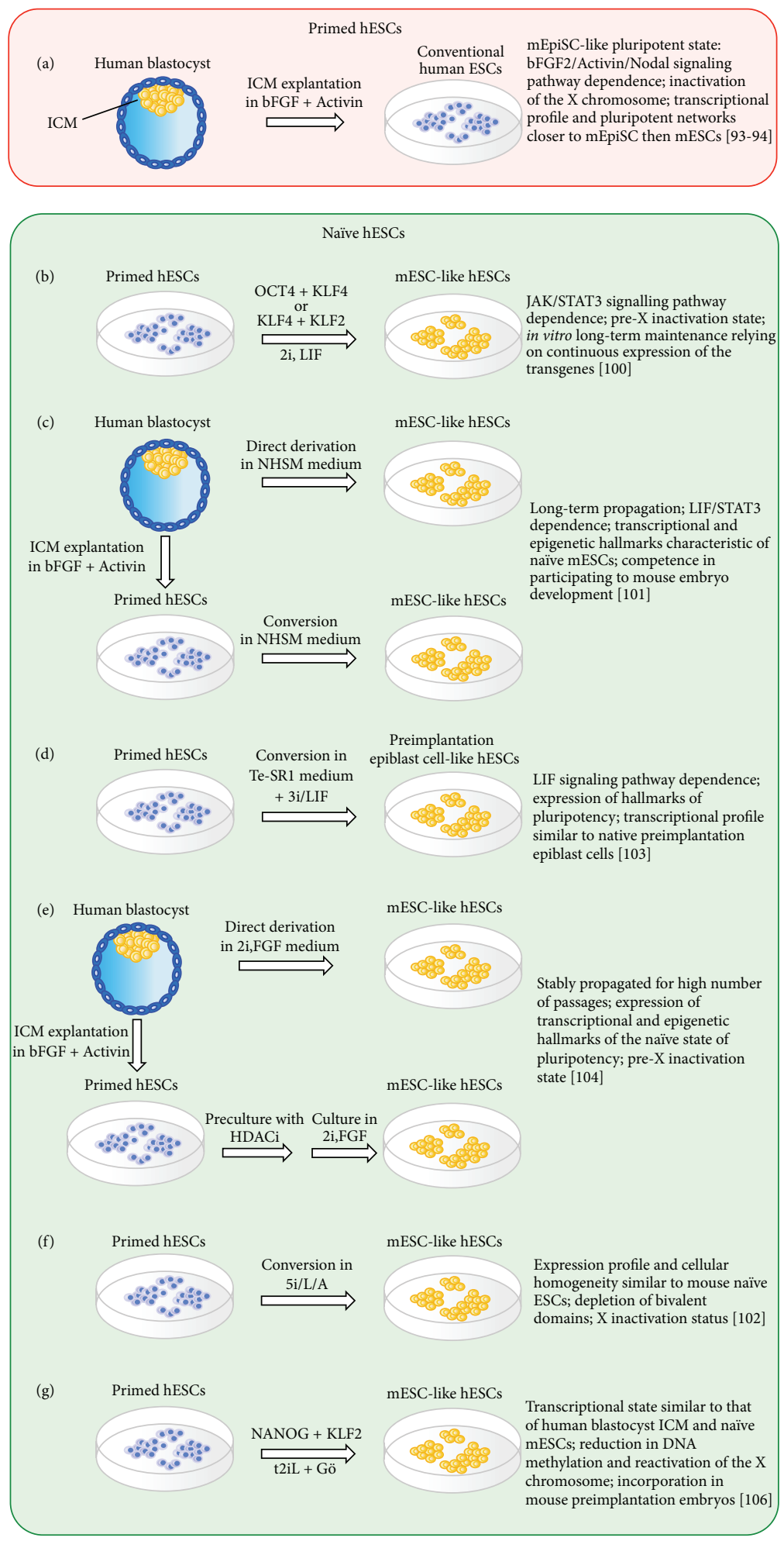

FIGURE 3: Schematic representation of culture conditions used to obtain primed and naïve pluripotent hESCs. (a) Conventional hESCs are derived from human blastocysts using a culture medium supplemented with bFGF and Activin A. hESCs derived in conventional culture conditions exhibit a pluripotent state more similar to murine EpiSCs than ESCs and are defined as primed hESCs. (b) hESCs with mESC-like characteristics can be produced by induced expression of either OCT4/KLF4 or KLF4/KLF2 transgenes in primed hESCs. Stable in vitro maintenance of these naïve hESCs requires continuous expression of the transgenes. (c, $d$, and e) Defined conditions allowing derivation of naïve hESCs from either already established primed hESCs or directly from blastocysts without the use of pluripotency-associated transgenes. (f) Conversion of primed hESCs into naïve state using five kinase inhibitors (5i) + LIF + Activin. (g) Short term expression of NANOG and KLF2 in primed hESC cells is sufficient to trigger ground state in hESCs cultivated in 2iL medium plus PKC inhibitor Gö6983. 
that similar transcriptional networks are able to maintain pluripotency in both hESCs and EpiSCs. In addition, female EpiSCs resemble female class II hESCs by the presence of an inactive X chromosome coated by Xist RNA and enriched for H3K27me3 marks [99].

One plausible scenario is that, during derivation and propagation, hESCs are unstable in conventional culture conditions and progress toward an EpiSC-like pluripotent state, and they are thus called primed hESCs [95] (Figure 3(a)).

The question was, did the naïve state exist for hESCs? In 2010, Rudolf Jaenish and coworkers demonstrated that it is possible to revert primed hESCs into a naïve state by ectopic expression of OCT4 and KLF4 or KLF4 and KLF2 plus 2i/LIF medium [100] (Figure 3(b)). These naïve hESCs appeared almost completely morphologically indistinguishable from mESCs, growing as packed dome colonies. In addition, maintenance of self-renewal depended on the JAK/STAT3 pathway, in contrast to conventional hESCs, which require Activin A signalling. Furthermore, the conversion of female primed hESCs into naïe hESCs is accompanied by $\mathrm{X}$ chromosome reactivation and changes in methylation of XIST promoter region, consistent with pre-X inactivation state [100]. These data supported the bona fide conversion of hESCs into a more immature state, although long-term propagation of naïve hESCs required constitutive expression of Klf4/Oct 4 or KLf4/Klf2 transgenes. The use of forskolin led to transient induction of KLF4 and KLF2 expression. These genetically unmodified forskolin-treated naïve hESCs could not be maintained for more than 15-20 passages, at which point they stopped proliferating and differentiated [100].

In 2013, the laboratory of Hanna established an optimized chemically defined medium, termed naïve human stem cell medium (NHSM), allowing robust and long-term maintenance of naïve hESCs [101]. These growth conditions were used to obtain naïe hESCs both from reversion of primed hESCs and from preimplantation blastocysts (Figure 3(c)). Transcriptional and epigenetic analyses revealed a functional overlap between mESCs and naïve hESCs. In addition, Gafni and coworkers showed that GFP-labelled hESCs microinjected into murine morulae at $2.5 \mathrm{dpc}$ colonized different tissues of chimeric murine embryo, indicating a functional competence [101]. Interestingly, the naive cells showed a higher integration into the ICM compared to that of primed pluripotent cells, suggesting that the generation of interspecies chimeras, through hESC injection into murine morulae, might be used as stringent assay to test human naive pluripotent state. However, the method does not seem to be reproducible to be used as a routine functional assay and further improvements are necessary [102].

The combination of three small molecules, the PI3K inhibitor PD0325901, the GSK3 inhibitor BIO, and the BMP signalling inhibitor Dorsomorphin, with LIF (referred to as $3 \mathrm{iL}$ ) allowed conversion of hESCs into a naïve-like state (Figure 3(d)). hESCs cultured in 3iL showed LIF signallingdependence and hallmarks of pluripotency including elevated expression of NANOG, KLF4, DPPA3, and TBX3 [103].

Transcriptome analysis confirmed the naïve state of hESCs cultured in 3iL. In addition, the different expression profile of $3 \mathrm{iL}$ hESCs compared to conventional hESCs is accompanied by global histone modification changes, resulting in derepression of preimplantation epiblast genes, as well as changes in OCT4, NANOG, and p300 binding sites, suggesting a rewiring of the pluripotency network [103]. The 3iL-induced hESC state narrows the gap between in vivo and in vitro pluripotent states.

Conversion of primed hESCs into naïve cells was also obtained by preculturing cells in HDACi, such as sodium butyrate and suberoylanilide hydroxamic acid (also known as SAHA or Vorinostat), followed by culture in $2 \mathrm{i}$ medium supplemented with FGF2 (2iF) [104] (Figure 3(e)). Preculturing in HDACi is an essential requisite for conversion into a naïve state, since exposure of primed hESCs to $2 \mathrm{i}$ induces differentiation. FGF2 is also a necessary component [104], supporting previously published data [101]. Using $2 \mathrm{iF}$, it was also possible to derive naïve cells directly from preimplantation human embryo. Curiously, when naïve hESCs directly derived from an embryo in $2 \mathrm{iF}$ were switched to $3 \mathrm{iL}$ or to $2 \mathrm{i}$, cells were able to grow stably for more than 60 passages, unlike cells grown in $2 \mathrm{iF}$ alone; though an increase in differentiation compared to $2 \mathrm{iF}$ conditions was observed [104].

Recently, Rudolf Jaenisch and coworkers have identified a combination of five kinase inhibitors (5i) able to induce and maintain in conventional hESCs OCT4 distal enhancer activity [102], an established molecular signature of "ground-state" pluripotency $[94,105]$. Indeed, provision of $5 \mathrm{i}$ supplemented with LIF and Activin A (5i/L/A) enables both conversion of primed into naïve hESCs in absence of reprogramming factors and the direct derivation of naive ES cells from human blastocysts [102] (Figure 3(f)). The authors compared their optimized culture conditions with those previously reported to induce a naïve pluripotent state $[101,103,104]$. Remarkably, substantial differences have been observed among the different cell lines in terms of OCT4 distal enhancer activity and transcriptional profile of markers typically associated with the self-renewal and pluripotency of mESCs.

Immediately after the publication of the Jaenish laboratory, Austin Smith and coworkers have described the production of naïve hESCs by short-term expression of NANOG and KLF2 transgenes in primed cells. The rewired cells culturing in $2 \mathrm{iL}$ medium in combination with the protein kinase C (PKC) inhibitor Gö6983 (t2iL + Gö) has been shown to sustain the pluripotent "ground-state" in absence of transgene expression [106] (Figure 3(g)). Interestingly the authors compared the transcriptional state of $\mathrm{t} 2 \mathrm{iL}+\mathrm{Gö}$ cells, conventional human PSCs, human blastocyst ICM, and naïve mESCs with NHSM, 3iL, and 5i/L/A cells reported to have undergone conversion to a naïve state [101-103]. The authors observed that while the transcriptional profile of $\mathrm{t} 2 \mathrm{iL}+\mathrm{Go}$ cells most resembled that of human blastocyst ICM and naïve $\mathrm{mES}$ cells, a significant difference from the conventional state was not apparent for lines cultured in NHSM, 3iL [106]. Upregulation of naïve markers and downregulation of lineage markers appeared comparable between $\mathrm{t} 2 \mathrm{iL}+\mathrm{Gö}$ and 5i/L/A hESCs; however some differences could be observed in the expression of epigenetic regulators, such as DNMT3A and TET1. In addition, Jaenish and coworkers reported X chromosome inactivation in contrast to $\mathrm{t} 2 \mathrm{iL}+\mathrm{Gö} \mathrm{hESCs.}$ 
All those findings suggest that, similarly to mouse, a naïve "ground-state" of pluripotency exists for hESCs. However, the initial comparative studies of the naïve human cell lines so far produced clearly indicate that the various culture conditions induce different pluripotent states, each showing similar features, but not identical, to those of naïve mESCs. The question whether differences exist in the pluripotent "ground-state" between human and mouse is still not clear. In addition, the off-targets effects of inducers/inhibitors added to culture medium should be taken in account: heterogeneity increases when using a broader combination of different inducers/inhibitors.

Further comparative studies of mouse and human preimplantation development and more extensive comparisons of the different naïve hPSCs are required to find an answer.

\section{Induced Pluripotent Stem Cells}

3.1. Cellular Reprogramming. The first evidence that somatic cells can be reprogrammed into a pluripotent state came from somatic cell nuclear transfer (SCNT) experiments performed in 1962, in which the nucleus of a differentiated cell was introduced into an enucleated oocyte giving rise to a cell, which, after stimulation, was capable of developing into an organism [111].

Four decades later, the possibility to revert the potency state of somatic nuclei was confirmed by fusion with ESCs $[112,113]$, suggesting that both unfertilized eggs and ESCs contain factors that are able to reprogramme somatic cells. Subsequently, in 2006 Takahashi and Yamanaka identified four genes, Oct4, Sox2, Klf4, and cMyc (OSKM) [6], which, when simultaneously overexpressed, are sufficient to induce reprogramming of mouse skin fibroblasts into pluripotent cells and called them induced pluripotent stem cells (iPSCs). Using the OSKM cocktail, iPSCs were also generated using human fibroblasts [7].

Many other groups have since reported reprogramming of several murine and human cell types, demonstrating the simplicity and reproducibility of the methodology, which can be applied to reprogramme most, if not all, somatic cells.

However, the efficiency of converting somatic cells into iPSCs is dramatically low; only approximately less than $1 \%$ of transfected fibroblasts become pluripotent. Extensive studies have been performed, modifying the OSKM cocktail in an attempt to improve efficiency. An exhaustive overview of those studies has been recently reported elsewhere and is therefore not further discussed here [114].

3.2. The Pluripotent "Ground State" of iPSCS. Murine iPSCs share all features of naïve mESCs, including morphology, expression of pluripotency-associated TFs, reactivation of X chromosome, ability to form teratomas, contribution to the germline of chimeric mice obtained by blastocyst injection, and generation of mice by tetraploid complementation [115118].

Similarly to mouse, human iPSCs express hESC-specific surface antigens, including stage-specific embryonic antigen(SSEA-) 3 and 4, tumour-related antigens (TRA-1-60, TRA1-81), pluripotency-associated TFs, high telomerase activity, and the ability to differentiate into cells of the three germ layers by teratoma formation [7, 119-121]. However, human iPSCs are in a primed state, as suggested by the presence of inactive X chromosome in female iPSCs [122-125]. As with hESCs, conversion of human iPSCs into a naive state can be achieved by culturing in defined media, as previously discussed. A visual comparison of murine and human PSC is shown in Figure 4.

3.3. Barriers to the Reprogramming Process. Although cell reprogramming is reproducible, the process is slow (around 2 weeks) and inefficient. Only a small fraction of transfected cells $(0.1-3 \%)$ become iPSCs [126], indicating that somatic cells must overcome barriers to revert to pluripotent state.

Apoptosis and senescence are the ultimate fate of the majority of cells induced by OSKM. Various reports showed that expression of Yamanaka factors in murine and human fibroblasts is able to induce p53 and p21 ${ }^{\mathrm{CIP} 1}$ [127-129]. Knockdown of p53 and/or induction of reprogramming in p53-null MEFs increase the efficiency of iPSC colony formation $[127,129,130]$, suggesting that the $\mathrm{p} 53 / \mathrm{p} 21$ pathways represent a barrier to reprogramming (Figure 5). Several groups also observed that expression of reprogramming factors activates the DNA damage response (DDR) pathway [128-130]. Thus, p53 might prevent the reprogramming of DNA-damaged cells by inducing apoptosis and senescence. Activation of the p53/p21 pathways highlights the tremendous stress to which cells are subjected during the process of reprogramming. Although reprogramming efficiency can be improved by interfering with crucial antiproliferative genes, the drawback of blocking important pathways that protect the cell from detrimental mutations is that it might affect the safety of resulting iPSCs, especially for medical applications.

The acquisition of pluripotency during reprogramming is accompanied by epigenetic remodelling of somatic cells, necessary to establish the transcriptional and epigenetic landscape defining the pluripotent state. Somatic cell identity is maintained and stabilized by epigenetic mechanisms, such as DNA methylation and histone modifications, which represent a potent barrier to the reprogramming process [126]. Reports by different groups showed that, in both mouse and human, iPSCs may retain residual transcriptional and epigenetic signatures characterizing their somatic origin [131136]. Incomplete erasure of tissue-specific DNA methylation and aberrant de novo methylation during reprogramming partially explain the persistent expression of somatic genes in iPSCs $[133,135]$. Inhibition of DNA methylation by 5 azacytidine $\left(5^{\prime}\right.$-AZA) or downregulation of DNA methyltransferase 1 (Dnmtl) increases reprogramming efficiency, demonstrating the functional linkage between DNA methylation and reprogramming [137].

All together, these findings provide evidence that DNA methylation is an obstacle to iPSC reprogramming. Trimethylation at $\mathrm{H} 3 \mathrm{~K} 9 \mathrm{me} 3$, associated with constitutive heterochromatin and imprinted genes, is also a barrier in somatic cell reprogramming $[42,138,139]$. Several studies reported a functional linkage between $\mathrm{H} 3 \mathrm{~K} 9 \mathrm{me} 3$ and reprogramming, showing that downregulation of either histone methyltransferases (HMTs), such as Setdb1, Ehmt1, Ehmt2, 


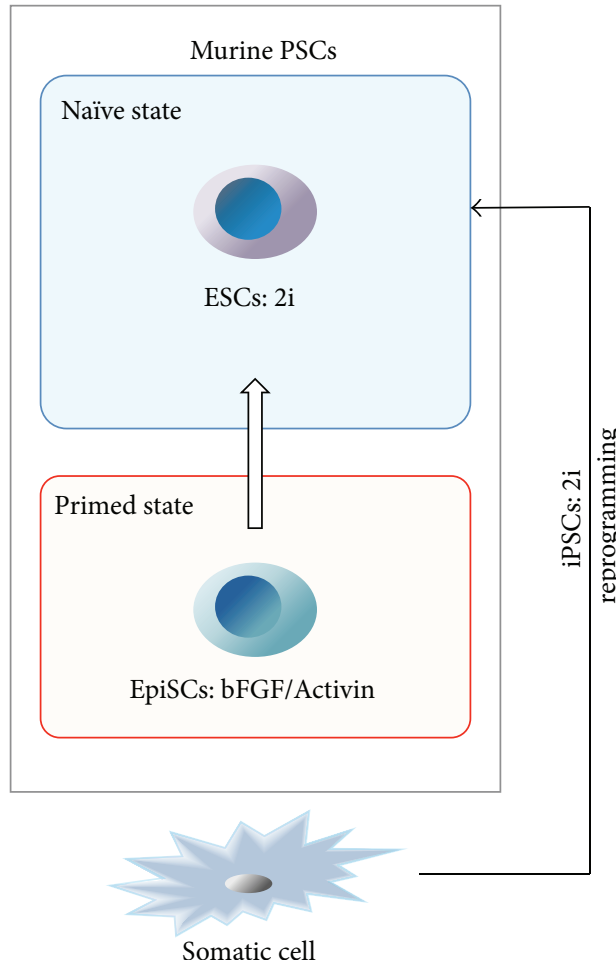

(a)

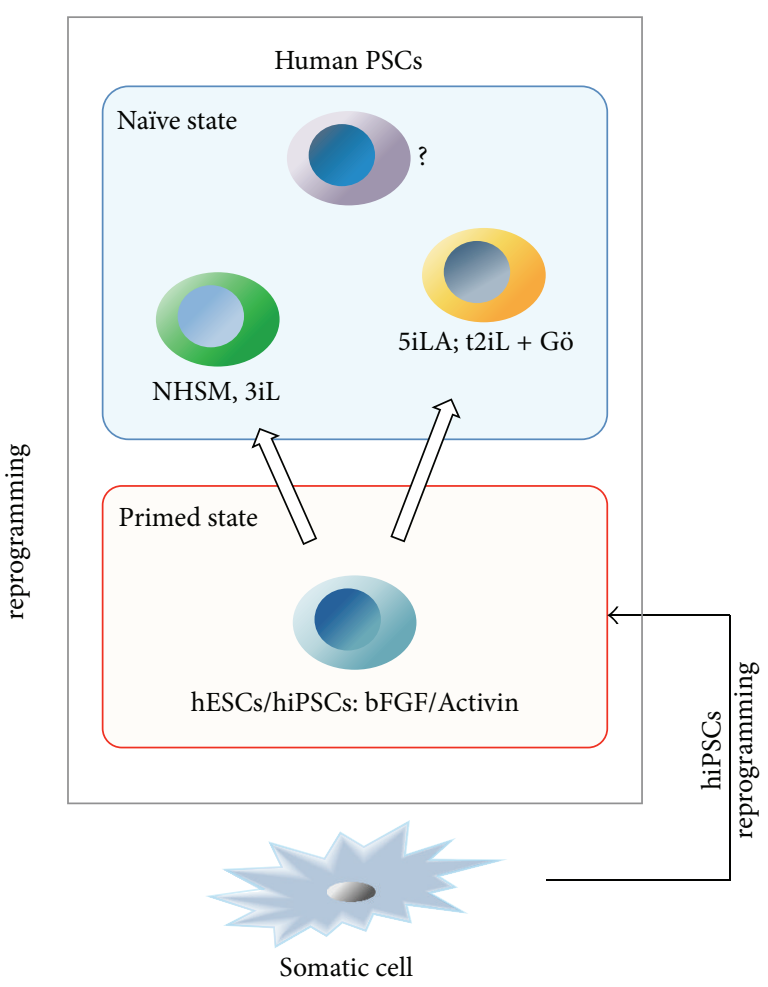

(b)

FIGURE 4: Visual comparison of murine and human PSCs. (a) In mouse, ESCs and EpiSCs are characterized by a different pluripotent state, called naïve and primed, respectively, which reflects their embryonic origin. The stability and homogeneity of mESCs cultured in $2 \mathrm{i}$ represent a developmental ground state closely reflective that of the ICM of preimplantation blastocysts. Pluripotent stem cell can be obtained also by reprogramming of somatic cells. Mouse iPSCs, cultured in 2i, show a ground state similar to mESCs. (b) Human ESCs and iPSCs cultured in presence of bFGF/Activin are in the primed state. Different conditions have been established to convert primed hESCs and hiPSCs into a naïve state. The initial comparative analysis of the naïve human cell lines clearly indicates that the various culture conditions induce different pluripotent states, each showing similar features, but not identical, to those of naïve mESCs. Whether the authentic pluripotent ground state of naïve hESCs is identical to that of mESCs, it is still to be determined.

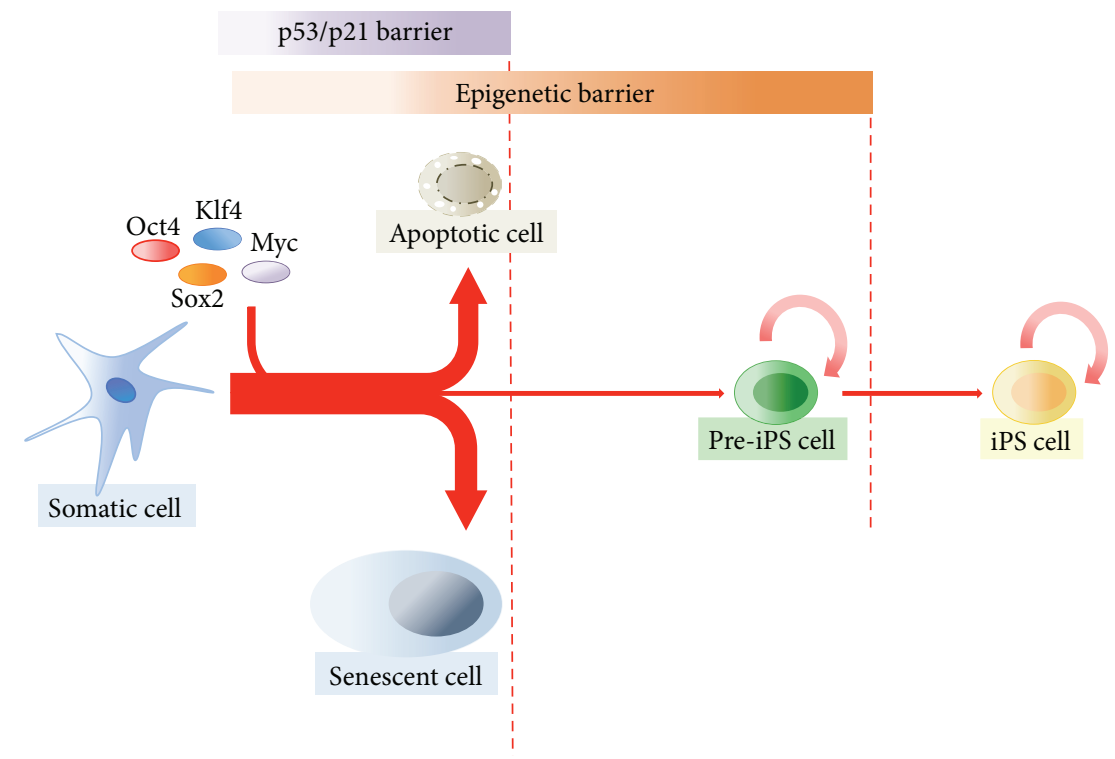

FIGURE 5: Scheme depicting cellular reprogramming and barriers affecting efficiency of the process. 
Suv39H1, and Suv39H2, or heterochromatic protein $1-\gamma$, an $\mathrm{H} 3 \mathrm{~K} 9 \mathrm{me} 3$ reader, enhances reprogramming efficiency.

iPSC reprogramming is a dynamic process involving several steps leading to repression of the somatic gene programme and reexpression of pluripotency-associated TFs. In pre-iPSCs, a clonal population of cells having already acquired an ESC-like morphology, the somatic gene expression programme is repressed, but pluripotency-associated TFs are not yet expressed, and they thus represent partially reprogrammed cells. Chromatin mark analysis of pre-iPSCs and MEFs showed enrichment of repressive $\mathrm{H} 3 \mathrm{~K} 9 \mathrm{me} 3$ marks compared to iPSCs stimulated by BMP signalling [137]. BMP effectors, such as Smad proteins, have thus been proposed as interacting with H3K9 HMTs, including Setdb1 and Suv39H1, to promote H3K9 trimethylation. Accordingly, knockdown of HMTs, such as Setdb1, Ehmt1, and Ehmt2, or of HP1 $\gamma$ in preiPSCs induces upregulation of the pluripotency genes Nanog, Gdf3, Zfp42, Dppa4, and Lin28 [138]. These findings suggest that erasure of the $\mathrm{H} 3 \mathrm{~K} 9 \mathrm{me} 3$ histone mark is a necessary step for reprogramming into naïve iPSCs.

A study mapping the initial interaction of OSKM factors with the human genome during the first 48 hours of reprogramming revealed the existence of genomic regions inaccessible to OSKM binding and enriched for H3K9me3 marks in pluripotency genes, such as Nanog and Sox2 [42]. These regions are refractory to OSKM binding due to the presence of H3K9me3 marks. Knockdown of SUV39H1/H2 during human iPSC reprogramming facilitates the access of OSKM factors to these regions, enhancing the efficiency and kinetics of reprogramming [42]. In a previous study, Lister and colleagues reported the identification of large regions showing aberrant non-CpG island methylation in human iPSCs not observed in ESCs [134]. These methylation "hot spots" enriched for H3K9me3 marks perfectly overlap with the OSKM binding regions identified by Soufi et al. $[42,140]$, supporting the hypothesis that heterochromatic marks disrupt the correct DNA methylation patterns in these regions and contribute to the "epigenetic memory" of iPSCs.

3.4. Advances in iPSC Technology: Toward Reprogramming Using Small Molecules. The discovery that somatic cells can be converted into a pluripotent state opened up the possibility of using iPSCs in cell transplantation therapies, as discussed later in this review. However, iPSC generation still presents several drawbacks, limiting the use of this promising resource in clinical applications.

The first iPSC reprogramming method utilized retroviral or lentiviral vectors for expression of OSKM factors. Although these vectors ensure high reprogramming efficiency, they can cause insertional mutagenesis resulting in harmful effects, such as tumour formation. Thus, for cell therapy purposes, alternative vectors were used to generate transgene integration-free iPSCs, including adenovirus [141], piggyBac transposon [142], episomal vectors [143], Sendai virus [144], plasmids [145], minicircle vectors [146], proteins [147], and synthetic RNAs [148]. However, achieving full reprogramming by reactivation of key pluripotency markers is a more lengthy process.
Another important issue that needs to be addressed is the presence in the cocktail of c-Myc, which may increase the risk of tumour formation. Mice generated by either blastocyst injection or tetraploid complementation with iPSCs are prone to develop tumours [149-151].

Current research in reprogramming is moving toward the development of transgene-free methodologies based on small molecules. Different compounds promoting dedifferentiation by acting on signalling pathways and epigenetic mechanisms have been identified.

The use of $5^{\prime}$-AZA and $2 \mathrm{i}$ was found to facilitate the transition of partially reprogrammed MEFs to fully reprogrammed iPSCs by promoting DNA demethylation [137, 152, 153].

HDACi, such as valproic acid, SAHA, and trichostatin A were shown to increase efficiency in recovering iPSC colonies $[154,155]$. Valproic acid proved to be the most potent in enabling efficient reprogramming of murine fibroblasts in absence of c-Myc [154] and human fibroblasts in absence of Klf4 and c-MYC [155]. Sodium butyrate was also reported to increase dedifferentiation of human fibroblasts in absence of both Klf4 and c-MYC transgenes [156].

Kenpaullone (KP), a GSK3 $\beta$ and CDK/cyclin complexes inhibitor (CDK1/cyclinB, CDK2/cyclinA/E, and CDK5/p25), was identified by molecule library screening as being able to replace Klf4 factor and increase reprogramming efficiency via an as yet unclear mechanism [157].

It has shown that the inhibition of TGF- $\beta$ signaling increases induction of iPSCs, replacing the requirement of Sox 2 and c-Myc [158]. Accordingly, a high-content chemical screening of small molecules led to the identification of the Tgf $\beta R 1$ inhibitor, E-616452, also called RepSox, able to induce reprogramming of MEF cells in absence of both Sox 2 and cMyc [159]. Although RepSox is able to replace Sox2 during reprogramming, it would act by inducing Nanog rather than Sox2 expression [159]. Other molecules have been shown to functionally replace Sox2, including inhibitors of the Src family kinases [160], CHIR99021 [161], and a combination of a L-channel calcium agonist, BayK8664 (BayK), with the G9a histone methyltransferase inhibitor BIX01294 [162].

Vitamin C enhances the efficiency of iPSC reprogramming using both mouse and human fibroblasts [163], by inducing demethylation of $\mathrm{H} 3 \mathrm{~K} 36 \mathrm{me} 2 / 3$ marks, mediated by Jumonji domain-containing histone demethylases (Jhdm) la and $1 b$ [164]. In combination with vitamin C, forced expression of Jhdmla was able to replace Klf4 and c-Myc, while Jhdmlb was able to replace Sox2, Klf4, and c-Myc confirming the key role of these enzymes in reprogramming. Furthermore, Jhdmlb represses the Ink4/ARF locus, a known block in reprogramming involved in senescence [165], by reducing H3K36me $2 / 3$ marks. In addition, Jhdmlb might cooperate with OCT4 for activation of the miR-302/367 miRNA cluster, probably facilitating OCT4 access [164].

In addition, generation of iPSCs via OSKM results in aberrant methylation of the imprinted Dlk1-Dio3 gene cluster, associated with the inability or reduced capacity of iPSCs to generate mice via tetraploid blastocyst injections, suggesting that stable repression of this locus is another roadblock in the reprogramming process $[166,167]$. Vitamin C improves iPSC generation by counteracting epigenetic silencing of 
the Dlk1-Dio3 locus. Vitamin C was shown to preserve an active histone configuration at Dlk1-Dio3 locus by preventing recruitment of Dnmt3a and consequent hypermethylation of the region, leading to stable silencing of maternal Dlk1-Dio3 transcripts [166].

Interestingly, a recent report showed that addition of vitamin $\mathrm{C}$ to $\mathrm{mESCs}$ promotes TET activity, leading to an increase in 5-hmC, followed by DNA demethylation of crucial gene promoters involved in pluripotency, suggesting another mechanism by which vitamin $\mathrm{C}$ might act during reprogramming [168].

$\mathrm{Li}$ and coworkers have identified a combination of small molecules, including VPA, CHIR99021, E-616452, and tranylcypromine (VC6T), able to induce MEFs reprogramming in combination with a single transgene, Oct4, thus replacing Sox2, Klf4, and c-Myc [169]. It has been proposed that VC6T may facilitate miPSCs generation by lowering several barriers, such as epigenetic modifications and intracellular signaling pathways, during reprogramming [169]. Similarly, Yuan and coworkers have identified a different combination of small molecules, including AMI-5, a protein arginine methyltransferase inhibitor, and A83-01, a TGF- $\beta$ inhibitor, that enable the production of miPSCs from MEFs using only Oct4 transgene expression [170].

Currently, in mouse it is possible to substitute the OSKM factors completely, avoiding the risk of insertional mutagenesis and with resulting iPSCs fulfilling all pluripotency and differentiation criteria. Hou and coworkers have shown a combination of small molecules, including VC6T, forskolin, and DNAZep (VC6TFZ), that enable MEFs reprogramming into pluripotent cells at a frequency of $0.2 \%$ [171]. Furthermore, the authors identified in forskolin, CHIR99021, E616452 and DZNep (C6FZ), critical and sufficient molecules to induce iPSCs reprogramming from MEFs in absence of OSKM, although with 10 -fold lower efficiency compared to VC6TFZ [171]. This study clearly shows that somatic reprogramming can be achieved using small molecule compounds. However, that goal has not been achieved yet in human. Oct4 transduction in combination with chemically defined compounds is necessary to generate efficiently hiPSCs [172$174]$, suggesting the needing to improve in human the reprogramming technology in perspective of cell-based therapies.

\section{Pluripotent Stem Cells: Applications, Problems, and Future Directions}

Self-renewal and pluripotency are fundamental characteristics of ESCs and iPSCs, making them attractive to academia and industry for their potential preclinical and clinical applications in the treatment of a wide array of diseases and pathological conditions.

Regenerative medicine is an exciting and fast moving field of research with the ambitious aim of using stem cells to replace tissues/organs damaged by injury, disease, or congenital defects. Because of their ability to differentiate into all the specialized cell types of an adult, pluripotent stem cells (PSCs), including human ESCs and iPSCs, are a promising source for cell-based therapies [175]. Therapeutic potential of
PSCs has been evaluated in preclinical studies, where PSCs transplantation has been applied to treat different diseases [176-185]. Noteworthy, cell therapy into animal models has shown beneficial effects, such as restoration of locomotion after spinal cord injury with hESC-derived oligodendrocyte [177], improved vision with hESC-derived retinal pigment epithelium (RPE) in blindness models [181], and improved cardiac function in a porcine ischemic cardiomyopathy model with iPSC-derived cardiomyocytes [186].

The potential benefit of both human ESCs and iPSCs has been also assessed in human clinical trials, summarized in Table 1. Early benefits to patients have been reported in some of these on-going trials, although final reports are few or not easily accessible [107].

In 2010, Geron Corporation launched the first clinical trial to evaluate the safety of hESC-derived oligodendrocyte progenitor cells (OPCs) in the treatment of spinal cord injuries (Table 1). Asterias Biotherapeutic continued this study, when Geron Corporation discontinued the cell therapy program. Although no official publication has been released, the results from the clinical trial have been presented at the American Society for Gene and Cell Therapy (ASGCT) in 2014. The data showed no serious adverse events due to the transplantation and, in four out of five patients, Magnetic Resonance Imaging (MRI) scan showed some positive effects in reducing the deterioration of spinal cord tissue.

In 2011 Ocata Therapeutics started two prospective clinical studies to establish safety and tolerability of subretinal transplantation of hESC-derived retinal pigment epithelium (RPE) in patients with Stargardt's macular dystrophy and dry age-related macular degeneration (AMD), two leading cause of blindness in the developed world $[187,188]$. The results of these studies provided evidence of medium-term safety, graft survival, and possible biological activity of pluripotent stem cell progeny in individuals affected by a disease [188]. Chabiotech Ltd. launched a phase I/IIa study to evaluate safety and tolerability of subretinal transplantation of hESC-derived RPE cells in two patients with advanced dry age-related macular degeneration (AMD) and two with Stargardt's macular dystrophy. Preliminary results showed no adverse events (tumour growth or other unexpected effects) and safety related to the therapy. Visual activity has been found to be improved in three out of four treated patients [189].

However, quality and safety issues must be fulfilled to produce clinical-grade human iPSCs suitable for cell therapies [187] and different issues still need to be addressed before translation of human iPSCs in clinical practice.

The use of viral systems to deliver reprogramming factors, which leads to permanent integration of oncogenes and results in potentially harmful genomic alterations, is a serious concern [188]. To overcome those issues, in mouse, a protocol transgene-independent that uses small molecules has been recently established, although the strategy is less efficient than viral transduction with OSKM factors and the reprogramming process is a more lengthy process [171]. In human, the same goal has not achieved yet and Oct4 transduction is required [172-174], suggesting the need to 
TABLE 1: Clinical trials using hESC- and hiPSC-derived products (modified by Trounson and McDonald [107]).

\begin{tabular}{|c|c|c|c|c|c|c|}
\hline Trial sponsor (location) & Targeted disease & Cell type & Phase & Clinical trial ID & Trial status & Reports \\
\hline Geron Corp. (USA) & Spinal cord injury & hES-derived OPCs & I & NCT01217008 & Complete & Not provided \\
\hline $\begin{array}{l}\text { Asterias Biotherapeutics } \\
\text { (USA) }\end{array}$ & Spinal cord injury & hES-derived OPCs & $\mathrm{I} / \mathrm{IIa}$ & NCT02302157 & On-going & Not available yet \\
\hline \multirow{3}{*}{ Ocata Therapeutics (USA) } & $\begin{array}{l}\text { Stargardt's macular } \\
\text { dystrophy }\end{array}$ & hES-derived RPE & $\mathrm{I} / \mathrm{II}$ & NCT01345006 & On-going & \multirow{3}{*}[108,109]{} \\
\hline & $\begin{array}{c}\text { Macular } \\
\text { degeneration }\end{array}$ & hES-derived RPE & $\mathrm{I} / \mathrm{II}$ & NCT01344993 & On-going & \\
\hline & $\begin{array}{c}\text { Myopic macular } \\
\text { degeneration }\end{array}$ & hES-derived RPE & $\mathrm{I} / \mathrm{II}$ & NCT02122159 & Not open yet & \\
\hline Pfizer (UK) & $\begin{array}{c}\text { Macular } \\
\text { degeneration }\end{array}$ & hES-derived RPE & I & NCT01691261 & On-going & Not available yet \\
\hline $\begin{array}{l}\text { Cell Cure Neurosciences } \\
\text { Ltd. (Israel) }\end{array}$ & $\begin{array}{c}\text { Macular } \\
\text { degeneration }\end{array}$ & hES-derived RPE & $\mathrm{I} / \mathrm{IIa}$ & NCT02286089 & On-going & Not available yet \\
\hline $\begin{array}{l}\text { Chabiotech Ltd. (South } \\
\text { Korea) }\end{array}$ & $\begin{array}{c}\text { Macular } \\
\text { degeneration }\end{array}$ & hES-derived RPEs & $\mathrm{I} / \mathrm{IIa}$ & NCT01674829 & On-going & {$[110]$} \\
\hline ViaCyte (USA) & $\begin{array}{c}\text { Type-1 diabetes } \\
\text { mellitus }\end{array}$ & hES-derived PP & $\mathrm{I} / \mathrm{II}$ & NCT02239354 & On-going & Not available yet \\
\hline $\begin{array}{l}\text { Assistance } \\
\text { Publique-Hôpitaux } \\
\text { de Paris (France) }\end{array}$ & Severe heart failure & $\begin{array}{c}\text { hES-derived CD15 } \\
+ \text { Isl-1 }+ \\
\text { progenitors }\end{array}$ & I & NCT02057900 & On-going & Not available yet \\
\hline $\begin{array}{l}\text { International Stem Cell } \\
\text { Corp. (Australia) }\end{array}$ & Parkinson disease & $\begin{array}{c}\text { hpESC-derived } \\
\text { NSC }\end{array}$ & I & NCT02452723 & Not open yet & - \\
\hline $\begin{array}{l}\text { RIKEN Center for } \\
\text { Developmental Biology }\end{array}$ & $\begin{array}{c}\text { Macular } \\
\text { degeneration }\end{array}$ & iPSC-derived RPEs & I & - & On-going & Not available yet \\
\hline
\end{tabular}

optimize the reprogramming strategies for the clinical safety of hiPSCs and improve the efficiency of the process.

Recent studies have provided evidence of genetic and epigenetic variations between different iPSC lines [189]. Some of the variations may be inherited from donor somatic cells or acquired during either the reprogramming process or extensive culturing [189]. Although such genetic and epigenetic variation affect only a small portion of the genome, they may change the properties of iPSCs and their derivatives, resulting in increased risk of tumorigenicity, altered differentiation potential of iPSCs, or impaired functional activity of iPSC derivatives [189]. Optimization of the reprogramming strategy and culture conditions may contribute in reducing or completely removing such variations [167].

Another important issue is the establishment of quality controls to ensure the safety of human iPSCs and their derivatives designated for downstream application [190]. Serum and mouse-derived feeder cells, used routinely to culture iPS cells, may transmit exogenous antigens or pathogens to reprogrammed cells, causing immune response or disease [191]. Thus, to produce clinical acceptable iPSCs, xeno-free cell culture systems should be used. Several investigations have been conducted and are still in progress, to develop animal-product-free culture system reducing the risks for patients [191]. This can be overcome by developing reliable and reproducible protocols for a direct and efficient differentiation of iPSCs in the desired tissue [192].

Furthermore, pluripotent identity and developmental potential of iPSCs should be characterized by teratoma formation [53]. iPSCs should also be differentiated in vitro to test their ability to produce the desired cell type. Evidence shows that epigenetic memories or incomplete reprogramming may affect differentiation properties of iPSCs [131-133], resulting either in a mixed population of differentiated cells or residual undifferentiated cells that may be tumorigenic when transplanted in vitro.

Evaluation of iPSC-derived products for cell therapy applications includes preclinical trials in healthy animals and disease models. Rodents are largely used in basic biology of iPSCs; however they may be not predictive of the efficacy. Large animals, such as pigs and monkeys, have been used in preclinical trials $[193,194]$, since they are more predictive due a more physiological similarity with humans and longer life span. However, there are disadvantages compared to rodents, including higher costs, more complex husbandry, and limited number of disease models.

Toxicity studies should also be performed on iPSCderived products through the analysis of major organs after transplantation of in vivo models [190].

While in USA clinical studies using iPSCs have not received regulatory approval from FDA [187], Japanese regulatory authorities gave the "green light." A Japanese woman was transplanted with iPSC-derived RPEs to treat macular degeneration [195]. This is the first world pilot study and may be the leader in many other applications of iPSC derivatives.

Cell patient-derived hiPSCs represent a wonderful cellular model to study several genetic diseases. Accordingly, in recent years, a large number of publications have reported 
that hiPSCs produced from patient with hereditary disease, after differentiation, are able to recapitulate different aspects associated with pathologies [196]. Although cell patientderived hiPSCs are limited by the fact that they represent a cellular model and they cannot recapitulate all the aspects of a disease and aspects, they remain an extremely valuable tool for the discovery of novel drugs with potential therapeutic applications and for toxicology studies [197]. Using hiPSCs for screening is a more cost-effective strategy than animal testing. In addition, the possibility of producing iPSCs from healthy donors and patients with hereditary or acquired diseases offers a more accurate system to evaluate the exact effect of a drug in a more physiological condition compared to the current cellular models represented by immortalized human cell lines [197]. This advantage combined with their ability to differentiate into a wide range of specialized cells will allow investigators to perform targeted preclinical toxicological in vitro trials [197]. Although cell-based in vitro assays allow high-throughput and/or high-content screens, they do not reflect the complex scenario in vivo. In vitro assays must be followed by animal model tests, the only way currently available to obtain a global understanding of crosstalk between different cell types and organs in a living organism, necessary to identify and characterize molecules and to allow their clinical translation from bench to bedside [186]. Moreover, the possibility to produce cell patient-derived iPSCs provided a solution to overcome the strong ethical concerns and immunological rejection that are currently key obstacles to the clinical practice of hESCs.

\section{Conclusions}

It is now indisputable that stem cell research is the way forward to tackle and possibly cure human diseases. PSCs, due to the capacity of differentiating into a wide range cell types, are of most interest where functional adult stem cells types are difficult to access expand or drive. In particular, hiPSCs represent an exciting alternative to embryonic cells, avoiding the ethical issues associated with their use and providing a better model for studying human diseases and possibly finding more effective therapies.

Although the progresses reached so far, further intensive investigations on the properties of human PSCs need to be performed both to understand the basic biology of pluripotency and cellular differentiation and to solve all the different issues associated with therapeutic applications. In addition, improvement of the current technologies should be performed to achieve clinical-grade human PSCs for safe cell therapies.

\section{Conflict of Interests}

The authors declare no conflict of interests.

\section{Authors' Contribution}

Antonio Romito and Gilda Cobellis contributed equally to this paper.

\section{Acknowledgments}

The authors wish to acknowledge Dr. Gabriella Minchiotti and Professor Lucia Altucci for ongoing scientific support and helpful discussion. Special thanks are due to Dr. Cristina D'Aniello for image and to CJ Fisher for linguistic editing.

\section{References}

[1] J. E. Till and E. McCulloch, "A direct measurement of the radiation sensitivity of normal mouse bone marrow cells," Radiation Research, vol. 14, pp. 213-222, 1961.

[2] M. Butler, G. C. Fonarow, M. R. Zile et al., "Developing therapies for heart failure with preserved ejection fraction: current state and future directions," Journal of the American College of Cardiology: Heart Failure, vol. 2, no. 2, pp. 97-112, 2014.

[3] A. M. Wobus and K. R. Boheler, "Embryonic stem cells: prospects for developmental biology and cell therapy," Physiological Reviews, vol. 85, no. 2, pp. 635-678, 2005.

[4] M. J. Evans and M. H. Kaufman, "Establishment in culture of pluripotential cells from mouse embryos," Nature, vol. 292, no. 5819, pp. 154-156, 1981.

[5] J. A. Thomson, "Embryonic stem cell lines derived from human blastocysts," Science, vol. 282, no. 5391, pp. 1145-1147, 1998.

[6] K. Takahashi and S. Yamanaka, "Induction of pluripotent stem cells from mouse embryonic and adult fibroblast cultures by defined factors," Cell, vol. 126, no. 4, pp. 663-676, 2006.

[7] K. Takahashi, K. Tanabe, M. Ohnuki et al., "Induction of pluripotent stem cells from adult human fibroblasts by defined factors," Cell, vol. 131, no. 5, pp. 861-872, 2007.

[8] A. G. Smith, "Embryo-derived stem cells: of mice and men," Annual Review of Cell and Developmental Biology, vol. 17, pp. 435-462, 2001.

[9] H. Niwa, T. Burdon, I. Chambers, and A. Smith, "Self-renewal of pluripotent embryonic stem cells is mediated via activation of STAT3," Genes and Development, vol. 12, no. 13, pp. 2048-2060, 1998.

[10] H. Hirai, P. Karian, and N. Kikyo, "Regulation of embryonic stem cell self-renewal and pluripotency by leukaemia inhibitory factor," Biochemical Journal, vol. 438, no. 1, pp. 11-23, 2011.

[11] Q.-L. Ying, J. Nichols, I. Chambers, and A. Smith, "BMP induction of Id proteins suppresses differentiation and sustains embryonic stem cell self-renewal in collaboration with STAT3," Cell, vol. 115, no. 3, pp. 281-292, 2003.

[12] S. Ye, P. Li, C. Tong, and Q.-L. Ying, "Embryonic stem cell selfrenewal pathways converge on the transcription factor Tfcp2l1," The EMBO Journal, vol. 32, no. 19, pp. 2548-2560, 2013.

[13] F. Itoh, T. Watabe, and K. Miyazono, "Roles of TGF-beta family signals in the fate determination of pluripotent stem cells," Seminars in Cell and Developmental Biology, vol. 32, pp. 98-106, 2014.

[14] J. Massagué, J. Seoane, and D. Wotton, "Smad transcription factors," Genes and Development, vol. 19, no. 23, pp. 2783-2810, 2005.

[15] E. E. Romero-Lanman, S. Pavlovic, B. Amlani, Y. Chin, and R. Benezra, "Id1 maintains embryonic stem cell self-renewal by upregulation of Nanog and repression of Brachyury expression," Stem Cells and Development, vol. 21, no. 3, pp. 384-393, 2012.

[16] T. Kunath, M. K. Saba-El-Leil, M. Almousailleakh, J. Wray, S. Meloche, and A. Smith, "FGF stimulation of the Erk1/2 signalling cascade triggers transition of pluripotent embryonic 
stem cells from self-renewal to lineage commitment," Development, vol. 134, no. 16, pp. 2895-2902, 2007.

[17] Q.-L. Ying, J. Wray, J. Nichols et al., "The ground state of embryonic stem cell self-renewal," Nature, vol. 453, no. 7194, pp. 519-523, 2008.

[18] J.-C. Yeo, J. Jiang, Z.-Y. Tan et al., "Klf2 is an essential factor that sustains ground state pluripotency," Cell Stem Cell, vol. 14, no. 6, pp. 864-872, 2014.

[19] H. Marks, T. Kalkan, R. Menafra et al., "The transcriptional and epigenomic foundations of ground state pluripotency," Cell, vol. 149, no. 3, pp. 590-604, 2012.

[20] L.-F. Chu, M. A. Surani, R. Jaenisch, and T. P. Zwaka, "Blimp1 expression predicts embryonic stem cell development in vitro," Current Biology, vol. 21, no. 20, pp. 1759-1765, 2011.

[21] J. Wray, T. Kalkan, S. Gomez-Lopez et al., "Inhibition of glycogen synthase kinase-3 alleviates Tcf3 repression of the pluripotency network and increases embryonic stem cell resistance to differentiation," Nature Cell Biology, vol. 13, no. 7, pp. 838-845, 2011.

[22] J. Hanna, S. Markoulaki, M. Mitalipova et al., "Metastable pluripotent states in NOD-mouse-derived ESCs," Cell Stem Cell, vol. 4, no. 6, pp. 513-524, 2009.

[23] J. Nichols, K. Jones, J. M. Phillips et al., "Validated germlinecompetent embryonic stem cell lines from nonobese diabetic mice," Nature Medicine, vol. 15, no. 7, pp. 814-818, 2009.

[24] D. Coronado, M. Godet, P.-Y. Bourillot et al., "A short G1 phase is an intrinsic determinant of naïve embryonic stem cell pluripotency," Stem Cell Research, vol. 10, no. 1, pp. 118-131, 2013.

[25] C. D. L. Folmes, P. P. Dzeja, T. J. Nelson, and A. Terzic, "Metabolic plasticity in stem cell homeostasis and differentiation," Cell Stem Cell, vol. 11, no. 5, pp. 596-606, 2012.

[26] N. Shyh-Chang, J. W. Locasale, C. A. Lyssiotis et al., "Influence of threonine metabolism on S-adenosylmethionine and histone methylation," Science, vol. 339, no. 6116, pp. 222-226, 2013.

[27] S. Comes, M. Gagliardi, N. Laprano et al., "L-proline induces a mesenchymal-like invasive program in embryonic stem cells by remodeling H3K9 and H3K36 methylation," Stem Cell Reports, vol. 1, no. 4, pp. 307-321, 2013.

[28] B. E. Bernstein, T. S. Mikkelsen, X. Xie et al., "A bivalent chromatin structure marks key developmental genes in embryonic stem cells," Cell, vol. 125, no. 2, pp. 315-326, 2006.

[29] T. S. Mikkelsen, M. Ku, D. B. Jaffe et al., "Genome-wide maps of chromatin state in pluripotent and lineage-committed cells," Nature, vol. 448, no. 7153, pp. 553-560, 2007.

[30] G. Ficz, M. R. Branco, S. Seisenberger et al., "Dynamic regulation of 5-hydroxymethylcytosine in mouse ES cells and during differentiation," Nature, vol. 473, no. 7347, pp. 398-402, 2011.

[31] W. A. Pastor, U. J. Pape, Y. Huang et al., "Genome-wide mapping of 5-hydroxymethylcytosine in embryonic stem cells," Nature, vol. 473, no. 7347, pp. 394-397, 2011.

[32] J. A. Hackett and M. A. Surani, "DNA methylation dynamics during the mammalian life cycle," Philosophical transactions of the Royal Society of London. Series B, Biological Sciences, vol. 368, no. 1609, Article ID 20110328, 2013.

[33] N. Grabole, J. Tischler, J. A. Hackett et al., "Prdm14 promotes germline fate and naive pluripotency by repressing FGF signalling and DNA methylation," EMBO Reports, vol. 14, no. 7, pp. 629-637, 2013.

[34] A. Sohni, M. Bartoccetti, R. Khoueiry et al., "Dynamic switching of active promoter and enhancer domains regulates Tetl and
Tet2 expression during cell state transitions between pluripotency and differentiation," Molecular and Cellular Biology, vol. 35, no. 6, pp. 1026-1042, 2015.

[35] R. Osorno, A. Tsakiridis, F. Wong et al., “The developmental dismantling of pluripotency is reversed by ectopic Oct 4 expression," Development, vol. 139, no. 13, pp. 2288-2298, 2012.

[36] J.-E. Dietrich and T. Hiiragi, "Stochastic patterning in the mouse pre-implantation embryo," Development, vol. 134, no. 23, pp. 4219-4231, 2007.

[37] G. Guo, M. Huss, G. Q. Tong et al., "Resolution of cell fate decisions revealed by single-cell gene expression analysis from zygote to blastocyst," Developmental Cell, vol. 18, no. 4, pp. 675$685,2010$.

[38] H. R. Scholer, R. Balling, A. K. Hatzopoulos, N. Suzuki, and P. Gruss, "Octamer binding proteins confer transcriptional activity in early mouse embryogenesis," The EMBO Journal, vol. 8, no. 9, pp. 2551-2557, 1989.

[39] H. R. Scholer, A. K. Hatzopoulos, R. Balling, N. Suzuki, and P. Gruss, "A family of octamer-specific proteins present during mouse embryogenesis: evidence for germline-specific expression of an Oct factor," The EMBO Journal, vol. 8, no. 9, pp. 2543-2550, 1989.

[40] S. Jerabek, F. Merino, H. R. Schöler, and V. Cojocaru, "OCT4: dynamic DNA binding pioneers stem cell pluripotency," Biochimica et Biophysica Acta, vol. 1839, no. 3, pp. 138-154, 2014.

[41] D. Esch, J. Vahokoski, M. R. Groves et al., "A unique Oct4 interface is crucial for reprogramming to pluripotency," Nature Cell Biology, vol. 15, no. 3, pp. 295-301, 2013.

[42] A. Soufi, G. Donahue, and K. S. Zaret, "Facilitators and impediments of the pluripotency reprogramming factors' initial engagement with the genome," Cell, vol. 151, no. 5, pp. 994-1004, 2012.

[43] Y. Miyanari and M.-E. Torres-Padilla, "Control of ground-state pluripotency by allelic regulation of Nanog," Nature, vol. 483, no. 7390, pp. 470-473, 2012.

[44] I. Chambers, D. Colby, M. Robertson et al., "Functional expression cloning of Nanog, a pluripotency sustaining factor in embryonic stem cells," Cell, vol. 113, no. 5, pp. 643-655, 2003.

[45] E. Abranches, E. Bekman, and D. Henrique, "Generation and characterization of a novel mouse embryonic stem cell line with a dynamic reporter of Nanog expression," PLOS ONE, vol. 8, no. 3, Article ID e59928, 2013.

[46] E. Abranches, A. M. V. Guedes, M. Moravec et al., "Stochastic NANOG fluctuations allow mouse embryonic stem cells to explore pluripotency," Development, vol. 141, no. 14, pp. 27702779, 2014.

[47] C. H. Hansen and A. van Oudenaarden, "Allele-specific detection of single mRNA molecules in situ," Nature Methods, vol. 10, no. 9, pp. 869-871, 2013.

[48] A. Filipczyk, K. Gkatzis, J. Fu et al., "Biallelic expression of nanog protein in mouse embryonic stem cells," Cell Stem Cell, vol. 13, no. 1, pp. 12-13, 2013.

[49] B. E. Reubinoff, M. F. Pera, C.-Y. Fong, A. Trounson, and A. Bongso, "Embryonic stem cell lines from human blastocysts: somatic differentiation in vitro," Nature Biotechnology, vol. 18, no. 4, pp. 399-404, 2000.

[50] M. Richards, C.-Y. Fong, W.-K. Chan, P.-C. Wong, and A. Bongso, "Human feeders support prolonged undifferentiated growth of human inner cell masses and embryonic stem cells," Nature Biotechnology, vol. 20, no. 9, pp. 933-936, 2002. 
[51] C. A. Cowan, I. Klimanskaya, J. McMahon et al., "Derivation of embryonic stem-cell lines from human blastocysts," The New England Journal of Medicine, vol. 350, no. 13, pp. 1353-1356, 2004.

[52] K. P. Smith, M. X. Luong, and G. S. Stein, "Pluripotency: toward a gold standard for human ES and iPS cells," Journal of Cellular Physiology, vol. 220, no. 1, pp. 21-29, 2009.

[53] R. L. Wesselschmidt, "The teratoma assay: an in vivo assessment of pluripotency," Methods in Molecular Biology, vol. 767, pp. 231241, 2011.

[54] D. James, S. A. Noggle, T. Swigut, and A. H. Brivanlou, "Contribution of human embryonic stem cells to mouse blastocysts," Developmental Biology, vol. 295, no. 1, pp. 90-102, 2006.

[55] A. Schnerch, C. Cerdan, and M. Bhatia, "Distinguishing between mouse and human pluripotent stem cell regulation: the best laid plans of mice and men," Stem Cells, vol. 28, no. 3, pp. 419-430, 2010.

[56] A. Rada-Iglesias and J. Wysocka, "Epigenomics of human embryonic stem cells and induced pluripotent stem cells: insights into pluripotency and implications for disease," Genome Medicine, vol. 3, no. 6, article 36, 2011.

[57] L. Dahéron, S. L. Opitz, H. Zaehres et al., "LIF/STAT3 signaling fails to maintain self-renewal of human embryonic stem cells," Stem Cells, vol. 22, no. 5, pp. 770-778, 2004.

[58] R. K. Humphrey, G. M. Beattie, A. D. Lopez et al., "Maintenance of pluripotency in human embryonic stem cells is STAT3 independent," Stem Cells, vol. 22, no. 4, pp. 522-530, 2004.

[59] R.-H. Xu, X. Chen, D. S. Li et al., "BMP4 initiates human embryonic stem cell differentiation to trophoblast," Nature Biotechnology, vol. 20, no. 12, pp. 1261-1264, 2002.

[60] D. James, A. J. Levine, D. Besser, and A. Hemmati-Brivanlou, "TGF $\beta /$ activin/nodal signaling is necessary for the maintenance of pluripotency in human embryonic stem cells," Development, vol. 132, no. 6, pp. 1273-1282, 2005.

[61] L. Vallier, M. Alexander, and R. A. Pedersen, "Activin/Nodal and FGF pathways cooperate to maintain pluripotency of human embryonic stem cells," Journal of Cell Science, vol. 118, no. 19, pp. 4495-4509, 2005.

[62] R.-H. Xu, R. M. Peck, D. S. Li, X. Feng, T. Ludwig, and J. A. Thomson, "Basic FGF and suppression of BMP signaling sustain undifferentiated proliferation of human ES cells," Nature Methods, vol. 2, no. 3, pp. 185-190, 2005.

[63] S. C. Bendall, M. H. Stewart, P. Menendez et al., "IGF and FGF cooperatively establish the regulatory stem cell niche of pluripotent human cells in vitro," Nature, vol. 448, no. 7157, pp. 1015-1021, 2007.

[64] R.-H. Xu, T. L. Sampsell-Barron, F. Gu et al., "NANOG is a direct target of TGFbeta/activin-mediated SMAD signaling in human ESCs," Cell Stem Cell, vol. 3, no. 2, pp. 196-206, 2008.

[65] S. Brown, T. E. O. Adrian, S. Pauklin et al., "Activin/nodal signaling controls divergent transcriptional networks in human embryonic stem cells and in endoderm progenitors," Stem Cells, vol. 29, no. 8, pp. 1176-1185, 2011.

[66] A. C. Mullen, D. A. Orlando, J. J. Newman et al., "Master transcription factors determine cell-type-specific responses to TGF- $\beta$ signaling," Cell, vol. 147, no. 3, pp. 565-576, 2011.

[67] L. Vallier, S. Mendjan, S. Brown et al., "Activin/Nodal signalling maintains pluripotency by controlling Nanog expression," Development, vol. 136, no. 8, pp. 1339-1349, 2009.

[68] P. Yu, G. Pan, J. Yu, and J. A. Thomson, "FGF2 sustains NANOG and switches the outcome of BMP4-induced human embryonic stem cell differentiation," Cell Stem Cell, vol. 8, no. 3, pp. 326334, 2011.

[69] A. D. Zoumaro-Djayoon, V. Ding, L.-Y. Foong, A. Choo, A. J. R. Heck, and J. Muñoz, "Investigating the role of FGF-2 in stem cell maintenance by global phosphoproteomics profiling," Proteomics, vol. 11, no. 20, pp. 3962-3971, 2011.

[70] V. M. Y. Ding, P. J. Boersema, L. Y. Foong et al., “Tyrosine phosphorylation profiling in FGF-2 stimulated human embryonic stem cells," PLoS ONE, vol. 6, no. 3, Article ID e17538, 2011.

[71] A. B. McLean, K. A. D’Amour, K. L. Jones et al., "Activin a efficiently specifies definitive endoderm from human embryonic stem cells only when phosphatidylinositol 3-kinase signaling is suppressed," Stem Cells, vol. 25, no. 1, pp. 29-38, 2007.

[72] J.-C. Yeo and H.-H. Ng, "The transcriptional regulation of pluripotency," Cell Research, vol. 23, no. 1, pp. 20-32, 2013.

[73] H. Fong, K. A. Hohenstein, and P. J. Donovan, "Regulation of self-renewal and pluripotency by Sox2 in human embryonic stem cells," Stem Cells, vol. 26, no. 8, pp. 1931-1938, 2008.

[74] L. Hyslop, M. Stojkovic, L. Armstrong et al., "Downregulation of NANOG induces differentiation of human embryonic stem cells to extraembryonic lineages," Stem Cells, vol. 23, no. 8, pp. 1035-1043, 2005.

[75] D. C. Hay, L. Sutherland, J. Clark, and T. Burdon, "Oct-4 knockdown induces similar patterns of endoderm and trophoblast differentiation markers in human and mouse embryonic stem cells," Stem Cells, vol. 22, no. 2, pp. 225-235, 2004.

[76] Y.-H. Loh, Q. Wu, J.-L. Chew et al., "The Oct4 and Nanog transcription network regulates pluripotency in mouse embryonic stem cells," Nature Genetics, vol. 38, no. 4, pp. 431-440, 2006.

[77] L. A. Boyer, I. L. Tong, M. F. Cole et al., "Core transcriptional regulatory circuitry in human embryonic stem cells," Cell, vol. 122, no. 6, pp. 947-956, 2005.

[78] R. Brandenberger, I. Khrebtukova, R. S. Thies et al., "MPSS profiling of human embryonic stem cells," BMC Developmental Biology, vol. 4, article 10, 2004.

[79] Z. Wang, E. Oron, B. Nelson, S. Razis, and N. Ivanova, "Distinct lineage specification roles for NANOG, OCT4, and SOX2 in human embryonic stem cells," Cell Stem Cell, vol. 10, no. 4, pp. 440-454, 2012.

[80] S. Rastan and E. J. Robertson, "X-chromosome deletions in embryo-derived (EK) cell lines associated with lack of Xchromosome inactivation," Journal of Embryology and Experimental Morphology, vol. 90, pp. 379-388, 1985.

[81] L. M. Hoffman, L. Hall, J. L. Batten et al., "X-inactivation status varies in human embryonic stem cell lines," Stem Cells, vol. 23, no. 10, pp. 1468-1478, 2005.

[82] O. Adewumi, B. Aflatoonian, L. Ahrlund-Richter et al., "Characterization of human embryonic stem cell lines by the International Stem Cell Initiative," Nature Biotechnology, vol. 25, no. 7, pp. 803-816, 2007.

[83] L. L. Hall, M. Byron, J. Butler et al., "X-inactivation reveals epigenetic anomalies in most hESC but identifies sublines that initiate as expected," Journal of Cellular Physiology, vol. 216, no. 2, pp. 445-452, 2008.

[84] Y. Shen, Y. Matsuno, S. D. Fouse et al., "X-inactivation in female human embryonic stem cells is in a nonrandom pattern and prone to epigenetic alterations," Proceedings of the National Academy of Sciences of the United States of America, vol. 105, no. 12, pp. 4709-4714, 2008.

[85] S. S. Silva, R. K. Rowntree, S. Mekhoubad, and J. T. Lee, "Xchromosome inactivation and epigenetic fluidity in human 
embryonic stem cells," Proceedings of the National Academy of Sciences of the United States of America, vol. 105, no. 12, pp. 4820-4825, 2008.

[86] T. Dvash, N. Lavon, and G. Fan, "Variations of X chromosome inactivation occur in early passages of female human embryonic stem cells," PLoS ONE, vol. 5, no. 6, Article ID el1330, 2010.

[87] S. V. Diaz Perez, R. Kim, Z. Li et al., "Derivation of new human embryonic stem cell lines reveals rapid epigenetic progression in vitro that can be prevented by chemical modification of chromatin," Human Molecular Genetics, vol. 21, no. 4, pp. 751764, 2012.

[88] C. J. Lengner, A. A. Gimelbrant, J. A. Erwin et al., "Derivation of pre-X inactivation human embryonic stem cells under physiological oxygen concentrations," Cell, vol. 141, no. 5, pp. 872-883, 2010.

[89] B. Fischer and B. D. Bavister, "Oxygen tension in the oviduct and uterus of rhesus monkeys, hamsters and rabbits," Journal of Reproduction and Fertility, vol. 99, no. 2, pp. 673-679, 1993.

[90] I. Okamoto, C. Patrat, D. Thépot et al., "Eutherian mammals use diverse strategies to initiate $\mathrm{X}$-chromosome inactivation during development," Nature, vol. 472, no. 7343, pp. 370-374, 2011.

[91] C. B. Ware, L. Wang, B. H. Mecham et al., "Histone deacetylase inhibition elicits an evolutionarily conserved self-renewal program in embryonic stem cells," Cell Stem Cell, vol. 4, no. 4, pp. 359-369, 2009.

[92] W. Fiskus, Y. Wang, A. Sreekumar et al., "Combined epigenetic therapy with the histone methyltransferase EZH2 inhibitor 3-deazaneplanocin A and the histone deacetylase inhibitor panobinostat against human AML cells," Blood, vol. 114, no. 13, pp. 2733-2743, 2009.

[93] I. G. M. Brons, L. E. Smithers, M. W. B. Trotter et al., "Derivation of pluripotent epiblast stem cells from mammalian embryos," Nature, vol. 448, no. 7150, pp. 191-195, 2007.

[94] P. J. Tesar, J. G. Chenoweth, F. A. Brook et al., "New cell lines from mouse epiblast share defining features with human embryonic stem cells," Nature, vol. 448, no. 7150, pp. 196-199, 2007.

[95] J. Nichols and A. Smith, "Naive and primed pluripotent states," Cell Stem Cell, vol. 4, no. 6, pp. 487-492, 2009.

[96] Y.-F. Chou, H.-H. Chen, M. Eijpe et al., "The growth factor environment defines distinct pluripotent ground states in novel blastocyst-derived stem cells," Cell, vol. 135, no. 3, pp. 449-461, 2008.

[97] B. Gerami-Naini, O. V. Dovzhenko, M. Durning, F. H. Wegner, J. A. Thomson, and T. G. Golos, "Trophoblast differentiation in embryoid bodies derived from human embryonic stem cells," Endocrinology, vol. 145, no. 4, pp. 1517-1524, 2004.

[98] R. S. P. Beddington and E. J. Robertson, "An assessment of the developmental potential of embryonic stem cells in the midgestation mouse embryo," Development, vol. 105, no. 4, pp. 733-737, 1989.

[99] G. Guo, J. Yang, J. Nichols et al., "Klf4 reverts developmentally programmed restriction of ground state pluripotency," Development, vol. 136, no. 7, pp. 1063-1069, 2009.

[100] J. Hanna, A. W. Cheng, K. Saha et al., "Human embryonic stem cells with biological and epigenetic characteristics similar to those of mouse ESCs," Proceedings of the National Academy of Sciences of the United States of America, vol. 107, no. 20, pp. 92229227, 2010.

[101] O. Gafni, L. Weinberger, A. A. Mansour et al., "Derivation of novel human ground state naive pluripotent stem cells," Nature, vol. 504, no. 7479, pp. 282-286, 2013.
[102] T. W. Theunissen, B. E. Powell, H. Wang et al., "Systematic identification of culture conditions for induction and maintenance of naive human pluripotency," Cell Stem Cell, vol. 15, no. 4, pp. 471-487, 2014.

[103] Y.-S. Chan, J. Göke, J.-H. Ng et al., "Induction of a human pluripotent state with distinct regulatory circuitry that resembles preimplantation epiblast," Cell Stem Cell, vol. 13, no. 6, pp. 663-675, 2013.

[104] C. B. Ware, A. Nelson, B. Mecham et al., "Derivation of naïve human embryonic stem cells," Proceedings of the National Academy of Sciences of the United States of America, vol. 111, no. 12, pp. 4484-4489, 2014.

[105] Y. I. I. Yeom, G. Fuhrmann, C. E. Ovitt et al., "Germline regulatory element of Oct-4 specific for the totipotent cycle of embryonal cells," Development, vol. 122, no. 3, pp. 881-894, 1996.

[106] Y. Takashima, G. Guo, R. Loos et al., "Resetting transcription factor control circuitry toward ground-state pluripotency in human,” Cell, vol. 158, no. 6, pp. 1254-1269, 2014.

[107] A. Trounson and C. McDonald, "Stem cell therapies in clinical trials: progress and challenges," Cell Stem Cell, vol. 17, no. 1, pp. 11-22, 2015.

[108] S. D. Schwartz, J.-P. Hubschman, G. Heilwell et al., "Embryonic stem cell trials for macular degeneration: a preliminary report," The Lancet, vol. 379, no. 9817, pp. 713-720, 2012.

[109] S. D. Schwartz, C. D. Regillo, B. L. Lam et al., "Human embryonic stem cell-derived retinal pigment epithelium in patients with agerelated macular degeneration and Stargardt's macular dystrophy: follow-up of two open-label phase $1 / 2$ studies," The Lancet, vol. 385, no. 9967, pp. 509-516, 2015.

[110] W. K. Song, K.-M. Park, H.-J. Kim et al., "Treatment of macular degeneration using embryonic stem cell-derived retinal pigment epithelium: preliminary results in Asian patients," Stem Cell Reports, vol. 4, no. 5, pp. 860-872, 2015.

[111] J. B. Gurdon, "The developmental capacity of nuclei taken from intestinal epithelium cells of feeding tadpoles," Journal of Embryology and Experimental Morphology, vol. 10, pp. 622-640, 1962.

[112] M. Tada, Y. Takahama, K. Abe, N. Nakatsuji, and T. Tada, "Nuclear reprogramming of somatic cells by in vitro hybridization with ES cells," Current Biology, vol. 11, no. 19, pp. 1553-1558, 2001.

[113] C. A. Cowan, J. Atienza, D. A. Melton, and K. Eggan, "Nuclear reprogramming of somatic cells after fusion with human embryonic stem cells," Science, vol. 309, no. 5739, pp. 1369-1373, 2005.

[114] I. K. Rony, A. Baten, J. A. Bloomfield, M. E. Islam, M. M. Billah, and K. D. Islam, "Inducing pluripotency in vitro: recent advances and highlights in induced pluripotent stem cells generation and pluripotency reprogramming," Cell Proliferation, vol. 48, no. 2, pp. 140-156, 2015.

[115] M. Wernig, A. Meissner, R. Foreman et al., "In vitro reprogramming of fibroblasts into a pluripotent ES-cell-like state," Nature, vol. 448, no. 7151, pp. 318-324, 2007.

[116] N. Maherali, R. Sridharan, W. Xie et al., "Directly reprogrammed fibroblasts show global epigenetic remodeling and widespread tissue contribution," Cell Stem Cell, vol. 1, no. 1, pp. 55-70, 2007.

[117] L. Kang, J. Wang, Y. Zhang, Z. Kou, and S. Gao, "iPS cells can support full-term development of tetraploid blastocystcomplemented embryos," Cell Stem Cell, vol. 5, no. 2, pp. 135138, 2009. 
[118] X.-Y. Zhao, W. Li, Z. Lv et al., "iPS cells produce viable mice through tetraploid complementation," Nature, vol. 461, no. 7260, pp. 86-90, 2009.

[119] J. Yu, M. A. Vodyanik, K. Smuga-Otto et al., "Induced pluripotent stem cell lines derived from human somatic cells," Science, vol. 318, no. 5858, pp. 1917-1920, 2007.

[120] W. E. Lowry, L. Richter, R. Yachechko et al., "Generation of human induced pluripotent stem cells from dermal fibroblasts," Proceedings of the National Academy of Sciences of the United States of America, vol. 105, no. 8, pp. 2883-2888, 2008.

[121] I.-H. Park, R. Zhao, J. A. West et al., "Reprogramming of human somatic cells to pluripotency with defined factors," Nature, vol. 451, no. 7175, pp. 141-146, 2008.

[122] J. Tchieu, E. Kuoy, M. H. Chin et al., "Female human iPSCs retain an inactive X chromosome," Cell Stem Cell, vol. 7, no. 3, pp. 329-342, 2010.

[123] A. Y. L. Cheung, L. M. Horvath, D. Grafodatskaya et al., "Isolation of MECP2-null Rett Syndrome patient hiPS cells and isogenic controls through X-chromosome inactivation," Human Molecular Genetics, vol. 20, no. 11, Article ID ddr093, pp. 2103-2115, 2011.

[124] O. Pomp, O. Dreesen, D. F. M. Leong et al., "Unexpected X chromosome skewing during culture and reprogramming of human somatic cells can be alleviated by exogenous telomerase," Cell Stem Cell, vol. 9, no. 2, pp. 156-165, 2011.

[125] S. Mekhoubad, C. Bock, A. S. De Boer, E. Kiskinis, A. Meissner, and K. Eggan, "Erosion of dosage compensation impacts human iPSC disease modeling," Cell Stem Cell, vol. 10, no. 5, pp. 595609, 2012.

[126] E. Apostolou and K. Hochedlinger, "Chromatin dynamics during cellular reprogramming," Nature, vol. 502, no. 7472, pp. 462-471, 2013.

[127] H. Hong, K. Takahashi, T. Ichisaka et al., "Suppression of induced pluripotent stem cell generation by the p53-p21 pathway," Nature, vol. 460, no. 7259, pp. 1132-1135, 2009.

[128] A. Banito, S. T. Rashid, J. C. Acosta et al., "Senescence impairs successful reprogramming to pluripotent stem cells," Genes and Development, vol. 23, no. 18, pp. 2134-2139, 2009.

[129] T. Kawamura, J. Suzuki, Y. V. Wang et al., "Linking the p53 tumour suppressor pathway to somatic cell reprogramming," Nature, vol. 460, no. 7259, pp. 1140-1144, 2009.

[130] R. M. Marión, K. Strati, H. Li et al., "A p53-mediated DNA damage response limits reprogramming to ensure iPS cell genomic integrity,' Nature, vol. 460, no. 7259, pp. 1149-1153, 2009.

[131] K. Kim, A. Doi, B. Wen et al., "Epigenetic memory in induced pluripotent stem cells," Nature, vol. 467, no. 7313, pp. 285-290, 2010.

[132] J. M. Polo, S. Liu, M. E. Figueroa et al., "Cell type of origin influences the molecular and functional properties of mouse induced pluripotent stem cells," Nature Biotechnology, vol. 28, no. 8, pp. 848-855, 2010.

[133] K. Kim, R. Zhao, A. Doi et al., "Donor cell type can influence the epigenome and differentiation potential of human induced pluripotent stem cells," Nature Biotechnology, vol. 29, no. 12, pp. 1117-1119, 2011.

[134] R. Lister, M. Pelizzola, Y. S. Kida et al., "Hotspots of aberrant epigenomic reprogramming in human induced pluripotent stem cells," Nature, vol. 471, no. 7336, pp. 68-73, 2011.

[135] Y. Ohi, H. Qin, C. Hong et al., "Incomplete DNA methylation underlies a transcriptional memory of somatic cells in human iPS cells," Nature Cell Biology, vol. 13, no. 5, pp. 541-549, 2011.
[136] S. Ruiz, D. Diep, A. Gore et al., "Identification of a specific reprogramming-associated epigenetic signature in human induced pluripotent stem cells," Proceedings of the National Academy of Sciences of the United States of America, vol. 109, no. 40, pp. 16196-16201, 2012.

[137] T. S. Mikkelsen, J. Hanna, X. Zhang et al., "Dissecting direct reprogramming through integrative genomic analysis," Nature, vol. 454, no. 7200, pp. 49-55, 2008.

[138] R. Sridharan, M. Gonzales-Cope, C. Chronis et al., "Proteomic and genomic approaches reveal critical functions of $\mathrm{H} 3 \mathrm{~K} 9$ methylation and heterochromatin protein- $1 \gamma$ in reprogramming to pluripotency," Nature Cell Biology, vol. 15, no. 7, pp. 872882, 2013.

[139] J. Chen, H. Liu, J. Liu et al., "H3K9 methylation is a barrier during somatic cell reprogramming into iPSCs," Nature Genetics, vol. 45, no. 1, pp. 34-42, 2013.

[140] A. Soufi and K. S. Zaret, "Understanding impediments to cellular conversion to pluripotency by assessing the earliest events in ectopic transcription factor binding to the genome," Cell Cycle, vol. 12, no. 10, pp. 1487-1491, 2013.

[141] M. Stadtfeld, M. Nagaya, J. Utikal, G. Weir, and K. Hochedlinger, "Induced pluripotent stem cells generated without viral integration," Science, vol. 322, no. 5903, pp. 945-949, 2008.

[142] K. Woltjen, I. P. Michael, P. Mohseni et al., "PiggyBac transposition reprograms fibroblasts to induced pluripotent stem cells," Nature, vol. 458, no. 7239, pp. 766-770, 2009.

[143] J. Yu, K. Hu, K. Smuga-Otto et al., "Human induced pluripotent stem cells free of vector and transgene sequences," Science, vol. 324, no. 5928, pp. 797-801, 2009.

[144] N. Fusaki, H. Ban, A. Nishiyama, K. Saeki, and M. Hasegawa, "Efficient induction of transgene-free human pluripotent stem cells using a vector based on Sendai virus, an RNA virus that does not integrate into the host genome," Proceedings of the Japan Academy Series B: Physical and Biological Sciences, vol. 85, no. 8, pp. 348-362, 2009.

[145] K. Okita, H. Hong, K. Takahashi, and S. Yamanaka, "Generation of mouse-induced pluripotent stem cells with plasmid vectors," Nature Protocols, vol. 5, no. 3, pp. 418-428, 2010.

[146] F. Jia, K. D. Wilson, N. Sun et al., "A nonviral minicircle vector for deriving human iPS cells," Nature Methods, vol. 7, no. 3, pp. 197-199, 2010.

[147] D. Kim, C.-H. Kim, J.-I. Moon et al., "Generation of human induced pluripotent stem cells by direct delivery of reprogramming proteins," Cell Stem Cell, vol. 4, no. 6, pp. 472-476, 2009.

[148] L. Warren, P. D. Manos, T. Ahfeldt et al., "Highly efficient reprogramming to pluripotency and directed differentiation of human cells with synthetic modified mRNA," Cell Stem Cell, vol. 7, no. 5, pp. 618-630, 2010.

[149] K. Okita, T. Ichisaka, and S. Yamanaka, "Generation of germline-competent induced pluripotent stem cells," Nature, vol. 448, no. 7151, pp. 313-317, 2007.

[150] M. Nakagawa, M. Koyanagi, K. Tanabe et al., "Generation of induced pluripotent stem cells without Myc from mouse and human fibroblasts,' Nature Biotechnology, vol. 26, no. 1, pp. 101$106,2008$.

[151] M. Tong, Z. Lv, L. Liu et al., "Mice generated from tetraploid complementation competent iPS cells show similar developmental features as those from ES cells but are prone to tumorigenesis," Cell Research, vol. 21, no. 11, pp. 1634-1637, 2011.

[152] J. Silva, O. Barrandon, J. Nichols, J. Kawaguchi, T. W. Theunissen, and A. Smith, "Promotion of reprogramming to ground 
state pluripotency by signal inhibition," PLoS Biology, vol. 6, no. 10, Article ID e253, 2008.

[153] E. Habibi, A. B. Brinkman, J. Arand et al., "Whole-genome bisulfite sequencing of two distinct interconvertible DNA methylomes of mouse embryonic stem cells," Cell Stem Cell, vol. 13, no. 3, pp. 360-369, 2013.

[154] D. Huangfu, R. Maehr, W. Guo et al., "Induction of pluripotent stem cells by defined factors is greatly improved by smallmolecule compounds," Nature Biotechnology, vol. 26, no. 7, pp. 795-797, 2008.

[155] D. Huangfu, K. Osafune, R. Maehr et al., "Induction of pluripotent stem cells from primary human fibroblasts with only Oct4 and Sox2," Nature Biotechnology, vol. 26, no. 11, pp. 1269-1275, 2008.

[156] P. Mali, B.-K. Chou, J. Yen et al., "Butyrate greatly enhances derivation of human induced pluripotent stem cells by promoting epigenetic remodeling and the expression of pluripotencyassociated genes," Stem Cells, vol. 28, no. 4, pp. 713-720, 2010.

[157] C. A. Lyssiotis, R. K. Foreman, J. Staerk et al., "Reprogramming of murine fibroblasts to induced pluripotent stem cells with chemical complementation of Klf4," Proceedings of the National Academy of Sciences of the United States of America, vol. 106, no. 22, pp. 8912-8917, 2009.

[158] N. Maherali and K. Hochedlinger, “Tgfbeta Signal Inhibition Cooperates in the Induction of iPSCs and Replaces Sox 2 and cMyc," Current Biology, vol. 19, no. 20, pp. 1718-1723, 2009.

[159] J. K. Ichida, J. Blanchard, K. Lam et al., "A small-molecule inhibitor of tgf- $\beta$ signaling replaces sox 2 in reprogramming by inducing nanog," Cell Stem Cell, vol. 5, no. 5, pp. 491-503, 2009.

[160] J. Staerk, C. A. Lyssiotis, L. A. Medeiro et al., "Pan-src family kinase inhibitors replace Sox 2 during the direct reprogramming of somatic cells," Angewandte Chemie International Edition, vol. 50, no. 25, pp. 5734-5736, 2011.

[161] W. Li, H. Zhou, R. Abujarour et al., "Generation of humaninduced pluripotent stem cells in the absence of exogenous Sox2," Stem Cells, vol. 27, no. 12, pp. 2992-3000, 2009.

[162] Y. Shi, C. Desponts, J. T. Do, H. S. Hahm, H. R. Schöler, and S. Ding, "Induction of pluripotent stem cells from mouse embryonic fibroblasts by Oct 4 and Klf4 with small-molecule compounds," Cell Stem Cell, vol. 3, no. 5, pp. 568-574, 2008.

[163] M. A. Esteban, T. Wang, B. Qin et al., "Vitamin C enhances the generation of mouse and human induced pluripotent stem cells," Cell Stem Cell, vol. 6, no. 1, pp. 71-79, 2010.

[164] T. Wang, K. Chen, X. Zeng et al., “The histone demethylases Jhdmla/lb enhance somatic cell reprogramming in a vitaminC-dependent manner," Cell Stem Cell, vol. 9, no. 6, pp. 575-587, 2011.

[165] H. Li, M. Collado, A. Villasante et al., "The Ink4/Arf locus is a barrier for iPS cell reprogramming," Nature, vol. 460, no. 7259, pp. 1136-1139, 2009.

[166] M. Stadtfeld, E. Apostolou, F. Ferrari et al., "Ascorbic acid prevents loss of Dlk1-Dio3 imprinting and facilitates generation of allg-iPS cell mice from terminally differentiated B cells," Nature Genetics, vol. 44, no. 4, pp. 398-405, 2012.

[167] B. W. Carey, S. Markoulaki, J. H. Hanna et al., "Reprogramming factor stoichiometry influences the epigenetic state and biological properties of induced pluripotent stem cells," Cell Stem Cell, vol. 9, no. 6, pp. 588-598, 2011.

[168] K. Blaschke, K. T. Ebata, M. M. Karimi et al., "Vitamin C induces Tet-dependent DNA demethylation and a blastocyst-like state in ES cells," Nature, vol. 500, no. 7461, pp. 222-226, 2013.
[169] Y. Li, Q. Zhang, X. Yin et al., "Generation of iPSCs from mouse fibroblasts with a single gene, Oct4, and small molecules," Cell Research, vol. 21, no. 1, pp. 196-204, 2011.

[170] X. Yuan, H. Wan, X. Zhao, S. Zhu, Q. Zhou, and S. Ding, "Brief report: combined chemical treatment enables Oct4-induced reprogramming from mouse embryonic fibroblasts," Stem Cells, vol. 29, no. 3, pp. 549-553, 2011.

[171] P. Hou, Y. Li, X. Zhang et al., "Pluripotent stem cells induced from mouse somatic cells by small-molecule compounds," Science, vol. 341, no. 6146, pp. 651-654, 2013.

[172] J. B. Kim, B. Greber, M. J. Arazo-Bravo et al., "Direct reprogramming of human neural stem cells by OCT4," Nature, vol. 461, no. 7264, pp. 649-653, 2009.

[173] S. Zhu, W. Li, H. Zhou et al., "Reprogramming of human primary somatic cells by OCT4 and chemical compounds," Cell Stem Cell, vol. 7, no. 6, pp. 651-655, 2010.

[174] Q. Wang, X. Xu, J. Li et al., "Lithium, an anti-psychotic drug, greatly enhances the generation of induced pluripotent stem cells," Cell Research, vol. 21, no. 10, pp. 1424-1435, 2011.

[175] V. Tabar and L. Studer, "Pluripotent stem cells in regenerative medicine: challenges and recent progress," Nature Reviews Genetics, vol. 15, no. 2, pp. 82-92, 2014.

[176] K. Nishimura and J. Takahashi, "Therapeutic application of stem cell technology toward the treatment of Parkinson's disease," Biological and Pharmaceutical Bulletin, vol. 36, no. 2, pp. 171-175, 2013.

[177] S. Kriks, J.-W. Shim, J. Piao et al., "Dopamine neurons derived from human ES cells efficiently engraft in animal models of Parkinson's disease," Nature, vol. 480, no. 7378, pp. 547-551, 2011.

[178] A. Kirkeby, S. Grealish, D. A. Wolf et al., "Generation of regionally specified neural progenitors and functional neurons from human embryonic stem cells under defined conditions," Cell Reports, vol. 1, no. 6, pp. 703-714, 2012.

[179] D. Doi, A. Morizane, T. Kikuchi et al., "Prolonged maturation culture favors a reduction in the tumorigenicity and the dopaminergic function of human ESC-derived neural cells in a primate model of Parkinson's disease," Stem Cells, vol. 30, no. 5, pp. 935-945, 2012.

[180] Y.-H. Rhee, J.-Y. Ko, M.-Y. Chang et al., "Protein-based human iPS cells efficiently generate functional dopamine neurons and can treat a rat model of Parkinson disease," Journal of Clinical Investigation, vol. 121, no. 6, pp. 2326-2335, 2011.

[181] R. D. Lund, S. Wang, I. Klimanskaya et al., "Human embryonic stem cell-derived cells rescue visual function in dystrophic RCS rats," Cloning and Stem Cells, vol. 8, no. 3, pp. 189-199, 2006.

[182] B. Lu, C. Malcuit, S. Wang et al., "Long-term safety and function of RPE from human embryonic stem cells in preclinical models of macular degeneration," Stem Cells, vol. 27, no. 9, pp. 21262135, 2009.

[183] F. W. Pagliuca, J. R. Millman, M. Gürtler et al., "Generation of functional human pancreatic $\beta$ cells in vitro," Cell, vol. 159, no. 2, pp. 428-439, 2014.

[184] Y. Shiba, S. Fernandes, W.-Z. Zhu et al., "Human ES-cell-derived cardiomyocytes electrically couple and suppress arrhythmias in injured hearts," Nature, vol. 489, no. 7415, pp. 322-325, 2012.

[185] J. Harding and O. Mirochnitchenko, "Preclinical studies for induced pluripotent stem cell-based therapeutics," The Journal of Biological Chemistry, vol. 289, no. 8, pp. 4585-4593, 2014.

[186] M. Kawamura, S. Miyagawa, K. Miki et al., "Feasibility, safety, and therapeutic efficacy of human induced pluripotent stem 
cell-derived cardiomyocyte sheets in a porcine ischemic cardiomyopathy model," Circulation, vol. 126, no. 11, supplement 1, pp. S29-S37, 2012.

[187] D. W. Fink Jr., "FDA regulation of stem cell-based products," Science, vol. 324, no. 5935, pp. 1662-1663, 2009.

[188] A. Higuchi, Q.-D. Ling, S. S. Kumar et al., "Generation of pluripotent stem cells without the use of genetic material," Laboratory Investigation, vol. 95, no. 1, pp. 26-42, 2015.

[189] G. Liang and Y. Zhang, "Genetic and epigenetic variations in iPSCs: potential causes and implications for application," Cell Stem Cell, vol. 13, no. 2, pp. 149-159, 2013.

[190] Y. Jung, G. Bauer, and J. A. Nolta, "Concise review: induced pluripotent stem cell-derived mesenchymal stem cells: progress toward safe clinical products," Stem Cells, vol. 30, no. 1, pp. 4247, 2012.

[191] T. Seki and K. Fukuda, "Methods of induced pluripotent stem cells for clinical application," World Journal of Stem Cells, vol. 7, no. 1, pp. 116-125, 2015.

[192] D. E. Cohen and D. Melton, "Turning straw into gold: directing cell fate for regenerative medicine," Nature Reviews Genetics, vol. 12, no. 4, pp. 243-252, 2011.

[193] C. Templin, R. Zweigerdt, K. Schwanke et al., “Transplantation and tracking of human-induced pluripotent stem cells in a pig model of myocardial infarction: assessment of cell survival, engraftment, and distribution by hybrid single photon emission computed tomography/computed tomography of sodium iodide symporter transgene expression," Circulation, vol. 126, no. 4, pp. 430-439, 2012.

[194] T. Kikuchi, A. Morizane, D. Doi et al., "Survival of human induced pluripotent stem cell-derived midbrain dopaminergic neurons in the brain of a primate model of Parkinson's disease," Journal of Parkinson's Disease, vol. 1, no. 4, pp. 395-412, 2011.

[195] S. Reardon and D. Cyranoski, "Japan stem-cell trial stirs envy," Nature, vol. 513, no. 7518, pp. 287-288, 2014.

[196] J. L. Sterneckert, P. Reinhardt, and H. R. Schöler, "Investigating human disease using stem cell models," Nature Reviews Genetics, vol. 15, no. 9, pp. 625-639, 2014.

[197] Y. Maury, M. Gauthier, M. Peschanski, and C. Martinat, "Human pluripotent stem cells for disease modelling and drug screening," BioEssays, vol. 34, no. 1, pp. 61-71, 2012. 

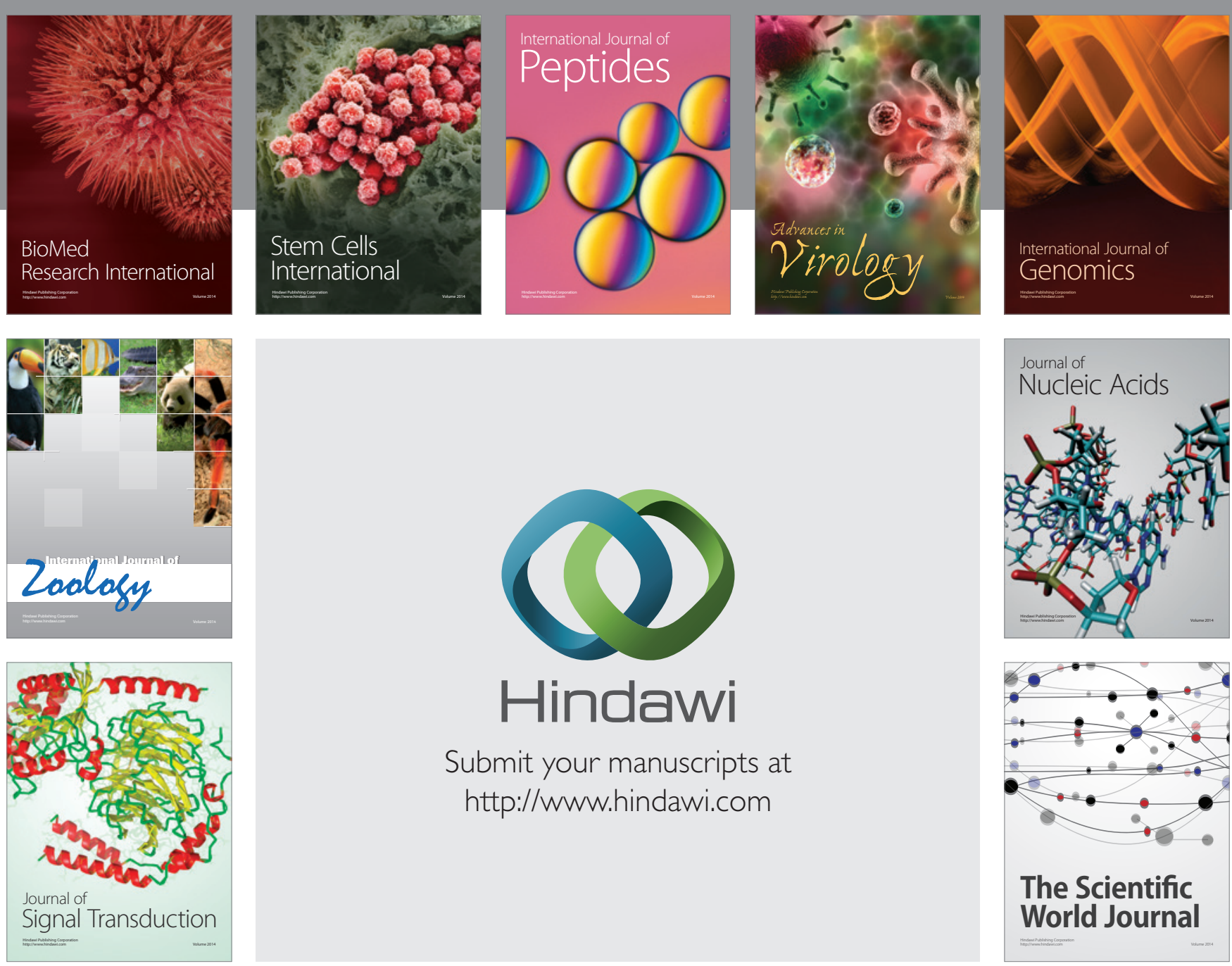

Submit your manuscripts at

http://www.hindawi.com
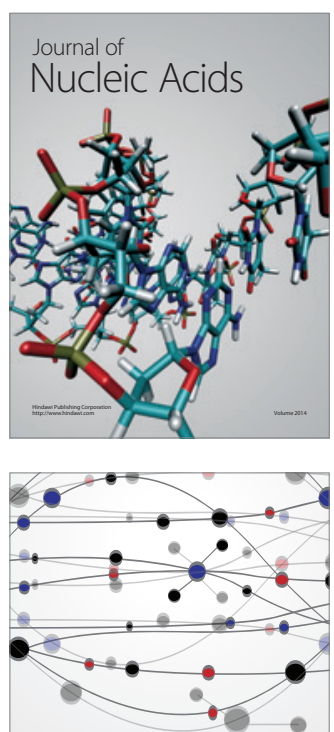

The Scientific World Journal
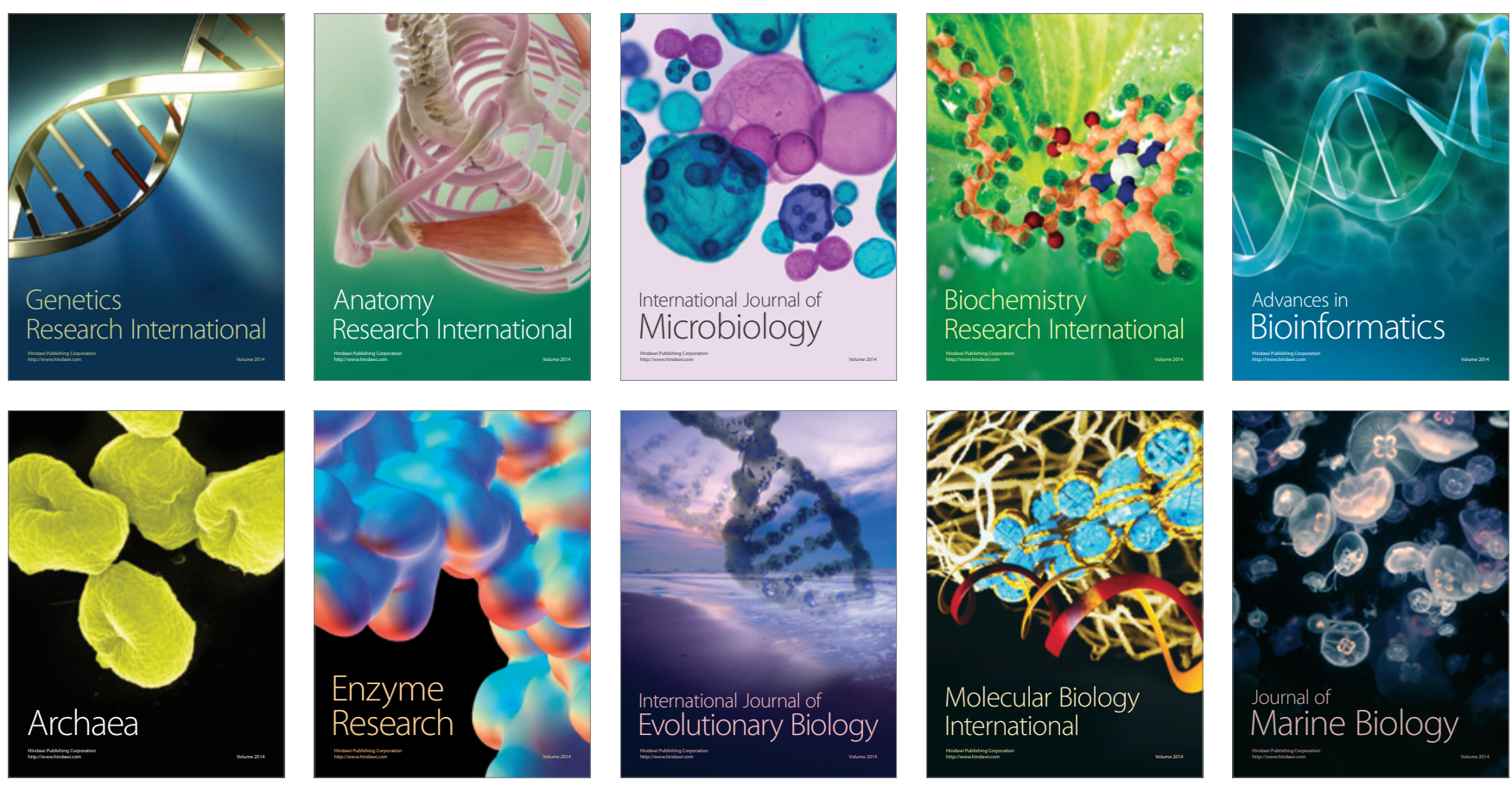